NBER WORKING PAPER SERIES

\title{
CAN COMPETITIVENESS PREDICT EDUCATION AND LABOR MARKET OUTCOMES? EVIDENCE FROM INCENTIVIZED CHOICE AND SURVEY MEASURES
}

\author{
Thomas Buser \\ Muriel Niederle \\ Hessel Oosterbeek \\ Working Paper 28916 \\ http://www.nber.org/papers/w28916 \\ NATIONAL BUREAU OF ECONOMIC RESEARCH \\ 1050 Massachusetts Avenue \\ Cambridge, MA 02138 \\ June 2021
}

Thomas Buser has received funding from the European Research Council (ERC) under the European Union's Horizon 2020 research and innovation programme. The views expressed herein are those of the authors and do not necessarily reflect the views of the National Bureau of Economic Research.

NBER working papers are circulated for discussion and comment purposes. They have not been peer-reviewed or been subject to the review by the NBER Board of Directors that accompanies official NBER publications.

(C) 2021 by Thomas Buser, Muriel Niederle, and Hessel Oosterbeek. All rights reserved. Short sections of text, not to exceed two paragraphs, may be quoted without explicit permission provided that full credit, including $(\subset$ notice, is given to the source. 
Can Competitiveness predict Education and Labor Market Outcomes? Evidence from Incentivized Choice and Survey Measures

Thomas Buser, Muriel Niederle, and Hessel Oosterbeek

NBER Working Paper No. 28916

June 2021

JEL No. C9,I20,J16,J24

\begin{abstract}
We assess the predictive power of two measures of competitiveness for education and labor market outcomes using a large, representative survey panel. The first is incentivized and is an online adaptation of the laboratory-based Niederle-Vesterlund measure. The second is an unincentivized survey question eliciting general competitiveness on an 11-point scale. Both measures are strong and consistent predictors of income, occupation, completed level of education and field of study. The predictive power of the new unincentivized measure for these outcomes is robust to controlling for other traits, including risk attitudes, confidence and the Big Five personality traits. For most outcomes, the predictive power of competitiveness exceeds that of the other traits. Gender differences in competitiveness can explain 5-10 percent of the observed gender differences in education and labor market outcomes.

Thomas Buser

Amsterdam School of Economics

University of Amsterdam

Roetersstraat 11

Room 3.51, Building E

1018 WB Amsterdam

The Netherlands

t.buser@uva.nl

Muriel Niederle

Department of Economics

579 Jane Stanford Way

Stanford University

Stanford, CA 94305-6072

and NBER

niederle@stanford.edu

Hessel Oosterbeek

Amsterdam School of Economics

University of Amsterdam

Roetersstraat 11

Room 3.60, Building E

1018 WB Amsterdam

The Netherlands

h.oosterbeek@uva.nl
\end{abstract}




\section{Introduction}

A growing literature documents the importance of individual traits such as conscientiousness and grit in determining education and labor market outcomes (Heckman and Rubinstein, 2001; Heckman, Stixrud, and Urzua, 2006; Mueller and Plug, 2006; Borghans et al., 2008; Almlund et al., 2011). We contribute to this literature by focusing on competitiveness, a trait emerging from the experimental economics literature. A number of recent studies indicate that individual preferences for competition are strongly associated with educational choices and early labor market outcomes (Buser, Niederle, and Oosterbeek, 2014; Reuben, Sapienza, and Zingales, 2015). ${ }^{1}$ These studies follow a large literature based on laboratory experiments documenting individual heterogeneity in competitiveness (Gneezy, Niederle, and Rustichini, 2003; Niederle and Vesterlund, 2007). Especially the gender gap in competitiveness found in the laboratory has attracted much interest because of its potential to explain gender differences in education and labor market outcomes (Bertrand, 2011).

Studies exploring the relevance of individual competitiveness for shaping careers typically link choices in incentivized experiments conducted in a laboratory or classroom setting to subsequent career choices and outcomes. ${ }^{2}$ This makes data collection expensive and logistically cumbersome. As a consequence, most studies use relatively small samples of students (or other selective groups which can be physically captured in one spot) and link the experimental data to short-term or medium-term outcomes. To take this literature forward, we elicit competitiveness through two measures that can be administered outside the laboratory setting. The first measure is incentivized and is an adaptation of the setup of the original Niederle-Vesterlund experiment such that it can be administered online. The second measure is an unincentivized survey question inspired by the work of Dohmen et al. (2011) and Falk et al. (2016) on other economic preferences.

This allows us to make the following main contributions. First, we show that willingness to compete as measured by an incentivized choice experiment strongly predicts earnings and occupation

\footnotetext{
${ }^{1}$ Buser, Niederle, and Oosterbeek (2014) and Buser, Peter, and Wolter (2017) show that an incentivized measure of competitiveness predicts specializing in more prestigious and math-heavy subjects for Dutch and Swiss students from the pre-university track of secondary school. Reuben, Sapienza, and Zingales (2015) show the same for the starting salaries and industry choices of MBA graduates. Other studies find that competitiveness predicts participating in a competitive high school entrance exam (Zhang, 2012), investment choices of entrepreneurs (Berge et al., 2015), choosing an ambitious college track in high-school (Almås et al., 2016), future salary expectations of undergraduate students (Reuben, Wiswall, and Zafar, 2017), and career choices at the vocational education level (Buser, Peter, and Wolter, 2018). Flory, Leibbrandt, and List (2015) and Samek (2019) run field experiments recruiting people for real jobs and show that compensation schemes which depend on relative performance deter women from applying relative to men.

${ }^{2}$ These studies commonly measure competitiveness using the design of Niederle and Vesterlund (2007), where participants choose between piece-rate and tournament incentives for their performance in a real-effort task. Competitiveness is then measured as the choice for tournament incentives conditional on prior performance on the task (and, sometimes, measures of confidence and risk attitudes). This literature has focused mainly on gender differences. Niederle and Vesterlund (2007) find that men are much more likely to compete than women. Their result has been replicated many times (see Niederle, 2016, Niederle and Vesterlund, 2011 and Croson and Gneezy, 2009 for surveys).
} 
conditional on education level, as well as education level and college major choice in a representative sample. Second, we show that our unincentivized survey question predicts the same outcomes in the same sample with comparable predictive power. Third, we show that our survey measure of competitiveness predicts these outcomes over and above other unincentivized trait measures that the education economics literature has typically focused on, including risk seeking, confidence and the big five personality traits, indicating that competitiveness is a separate influential trait that is not captured by these other, more traditionally used traits. Our new, validated questionnaire measure will enable researchers in all social science fields to measure this trait in large scale surveys, opening new avenues for exploring individual and group differences in competitiveness, their origins, and their consequences for career choices and labor market outcomes.

Our questionnaire measure is inspired by the seminal work of Dohmen et al. (2011) on risk preferences and consists of the question "How competitive do you consider yourself to be?", where respondents pick a number on a scale from zero to ten. We included this measure, as well as an incentivized choice experiment based on the design of Niederle and Vesterlund (2007), in two of the monthly rounds of an online survey panel which is representative of the Dutch population. The survey question was included in one of the waves in 2017 and was sent to all members of the panel. The incentivized measure was included in one of the waves in 2018 and was sent to a random subsample of the respondents of the survey question. Because there was a full year and several unrelated survey rounds in between the two waves, it is unlikely that participants in the incentivized experiment were aware of the connection between the experiment and the survey question.

Eliciting our competitiveness measures in this panel allows us to leverage the rich information that has already been collected from the panel participants. Besides data on education and labor market outcomes, the dataset also contains information about many individual traits such as confidence, self-esteem and the big five personality traits (extroversion, agreeableness, conscientiousness, stability and intellectual openness). To this, we added a measure of risk preferences (Dohmen et al., 2011). We can therefore investigate whether competitiveness predicts education and labor market variables on top of these other traits. Moreover, we can compare the predictive power of competitiveness to that of the other personality traits. This data also allows us to validate our survey question not only by computing its correlation with the incentivized choice at the individual level but also by checking whether both measures predict relevant career outcomes in a similar way.

Several papers in psychology have developed scales to measure aspects of competitiveness (Griffin-Pierson, 1990; Ryckman et al., 1990; Smither and Houston, 1992; Houston et al., 2002; Newby and Klein, 2014). None of these has been widely adopted and none has, to our knowledge, been linked to education or labor market outcomes in a large sample. Houston et al. (2015) correlate their competitiveness scale with occupational interests in a sample of 149 undergraduate students, finding a positive correlation with the corresponding O*NET rating of the occupation's 
level of competition. ${ }^{3}$

In economics, Bönte and Piegeler (2013) use the Eurobarometer 283 survey on entrepreneurship which contains an unincentivized measure of competitiveness. ${ }^{4}$ They show this measure is positively correlated with entrepreneurship. Bönte, Lombardo, and Urbig (2017) elicit both an incentivized measure of competitiveness and several unincentivized questions taken from different competitiveness scales from the psychology literature. In a sample of 186 students, they find a significant correlation between incentivized and self-reported competitiveness. They correlate both with interest in a managerial career and find a significant correlation with a subset of the self-reported measures, but not with the incentivized choice. Boschini et al. (2019) collected incentivized measures of competitiveness and risk preferences using telephone interviews with a random sample of 926 people from the Swedish population. Their paper focuses on gender differences in competitiveness and risk preferences, finding no gender difference in competitiveness when participants perform a language task and replicating the lab finding that men are more likely to compete in a math task. Regressions of competitiveness on gender, age, age squared, income, education and gender of the interviewer show positive conditional associations between competitiveness and income and between competitiveness and education. The results do not show how strong a predictor competitiveness is for education and income, nor can the authors condition on other personality traits or compare the predictive power of competitiveness with that of other traits (other than risk preferences). Fallucchi, Nosenzo, and Ernesto (2020) conducted a validation exercise to obtain a survey measure of preference for competition on a sample of 90 students from the University of Luxembourg. Of the eight survey questions they included, the statement "Competition brings the best out of me" correlates highest with an incentivized competition choice elicited two weeks later. $^{5}$

We elicit both our incentivized measure and our unincentivized measure of competitiveness in a large and representative sample that contains a rich set of career outcomes and psychological traits. Our results show that both measures are strong predictors of the same education and labor market outcomes. Conditional on performance in the task, gender, age, education level, risk preferences, confidence and the big five personality traits, individuals who compete in the experiment earn significantly more and are much more likely to hold a high-level managerial or professional position. Individuals who compete are also more likely to have gone to college and, conditional on having gone to college, chose more prestigious study majors that lead to higher salaries. We find the same effects for people who score themselves higher on competitiveness in our new survey question. Comparing the predictive power of different traits, competitiveness is

\footnotetext{
${ }^{3}$ Defined as the extent to which the "job requires the worker to compete or to be aware of competitive pressure". O*NET stands for Occupational Information Network.

${ }^{4}$ The extend to which a respondent agrees with the statement "I like situations in which I compete with others". Bönte (2015) uses the same data to study cross-country differences in the competitiveness gender gap.

${ }^{5}$ They further find that a group of athletes agreed more with this statement than a group of non-athletes of the same age.
} 
consistently among the strongest predictors. The fact that the incentivized and unincentivized measures predict the same outcomes justifies the use of the unincentivized survey question as a valid measure of competitiveness. This makes it possible to elicit competitiveness in large-scale representative survey panels or cross-country surveys in the future.

Our results also contribute to a recent discussion in experimental economics about whether competitiveness is a separate trait capturing a preference for competition or whether it is a composite measure of confidence, risk preferences and other previously studied individual traits (Gillen, Snowberg, and Yariv, 2019; van Veldhuizen, 2017). We present results that show that competitiveness and risk preferences predict different outcomes. Conditional on controls including confidence and the big five personality traits, none of the education and labor market outcomes we study are predicted by risk attitudes. But conversely, a range of risky, but not inherently competitive choices that were studied by Dohmen et al. (2011), such as investing in stocks, smoking or being self-employed, are predicted by risk attitudes but not by competitiveness. Likewise, competitiveness tends to predict education and labor market variables more strongly than each of several measures of confidence. We conclude that competitiveness is not well captured by either risk attitudes or confidence or by the big five personality traits and should therefore be considered as a new, distinctive trait.

With both our incentivized and our unincentivized measure, we replicate the finding of a gender gap in competitiveness. We analyze to what extent the gender difference in competitiveness can account for gender differences in education and labor market outcomes. Controlling for our survey measure reduces the estimated gender gap in earnings by about 5 percent (10 percent for collegeeducated individuals) and the gender differences in occupation and chosen college major by about 10 percent. These effects are higher than those obtained for most of the other traits. These results contribute to a recent discussion on whether differences in personality and preferences can partially explain gender differences in labor market outcomes (Bertrand, 2011; Cortes and Pan, 2018; Shurchkov and Eckel, 2018).

A further important question is whether the positive link between competitiveness and career outcomes hides negative sides of competitiveness. In particular, it may be that increased competitiveness comes at the cost of life satisfaction, personal relationships or social orientation. However, we find that - conditional on gender, age, education level, risk preferences, confidence, and the big five personality traits - individuals who rate themselves as more competitive also judge themselves to be happier and more satisfied with their lives, are less likely to take medication for depression or anxiety, are no less likely to have a partner or be married, feel closer to other people in general, have similar levels of trust, and give more importance to being helpful and loving.

The remainder of this paper is organized as follows. The next section introduces the survey and incentivized measures of competitiveness and the other variables from the LISS panel that we use in the analysis. Section 3 presents the empirical findings in five parts. It first reports results for the relation between the incentivized competitiveness measure and education and labor market 
outcomes. It next presents similar results for the survey measure of competitiveness and compares the predictive power of the survey measure to those of other relevant trait measures (risk attitudes, confidence and the the big five personality traits). The third part compares competitiveness and risk attitudes in detail. The fourth part looks at wether competitiveness is associated with personal wellbeing and social preferences. Finally, the fifth part examines to which extent gender differences in competitiveness can explain gender differences in education and labor market outcomes. Section 4 summarizes and concludes.

\section{Data}

We collected our data on the Dutch LISS panel (Longitudinal Internet Studies for the Social sciences), an ongoing online survey panel. The panel has been in full operation since October 2007. It is based on a true probability sample of households drawn from the population register by Statistics Netherlands (www.lissdata.nl). Panel members answer to yearly repeated "core" questionnaires which cover a large range of topics including work, education, wealth, family and, importantly for our purposes, personality. On top of this, researchers can pay to run questionnaires on the panel, including incentivized experiments, which can then be linked to all other data that is available on the respondents. All LISS data, including researcher-run questionnaires, is publicly available to all researchers.

The timeline of our data collection is as follows. In March 2017, we collected two survey measures of competitiveness, as well as measures of risk preferences and of confidence. This questionnaire was aimed at all panel members. A year later, in April 2018, we ran the incentivized choice experiment on a subsample which represents a random selection of working-age panel members. In this section, we explain the measures we collected, the trait measures already present in the LISS questionnaires, and the education and labor market variables.

\subsection{Survey measure of competitiveness}

In March 2017, we included two survey questions in the LISS panel aimed at eliciting respondents' competitiveness. The first question, which is the one we use for our main analyses, asks respondents about their general competitiveness through the question "How competitive do you consider yourself to be? Please choose a value on the scale below, where the value 0 means 'not competitive at all' and the value 10 means 'very competitive'." This question is a variation on the general risk preference question validated in Dohmen et al. (2011). ${ }^{6}$ The second question describes the experimental design of Niederle and Vesterlund (2007) and asks respondents whether they would choose piece rate or tournament compensation in the hypothetical case that they would participate

\footnotetext{
${ }^{6}$ Their question reads "How do you see yourself: Are you a person who is generally willing to take risks, or do you try to avoid taking risks?" The answering scale runs from 0 (completely unwilling) to 10 (completely willing).
} 
in this choice experiment. ${ }^{7}$ We also asked the general risk preference question of Dohmen et al. (2011), and - to measure confidence on the task - we elicited how well the respondents think they would perform in the Niederle-Vesterlund numbers task compared to other panel members. ${ }^{8}$ The survey was answered by 5255 individuals, 3082 of whom are between 25 and 65 years old. This corresponds to a response rate of $86 \%$.

From our analysis of the data, we conclude that the general question results in a better measure of competitiveness than the hypothetical choice question. Both are correlated significantly with the incentivized measure but the general measure shows stronger associations with education and labor market variables. ${ }^{9}$ For readability we will therefore, in the main text, only report results based on the general competitiveness question. Results for the hypothetical competitiveness question are very similar and are reported in Appendix B. There, we also show that while the first, simpler measure, predicts outcomes better, predictive power can still be meaningfully increased by including both measures jointly.

\subsection{Incentivized choice experiment}

In the original Niederle-Vesterlund choice experiment (Niederle and Vesterlund, 2007), subjects are seated behind computer screens in a laboratory to perform the same task during three subsequent rounds. In the first round they are paid for their performance through a piece rate. In the second round they are paid in the form of a winner-takes-all tournament. For the third round, subjects have to choose whether they want to be compensated in the form of a piece rate or a tournament. The task that subjects perform in this original experiment is to add up sets of five two-digit numbers. The instructions tell the participants that the use of a calculator is not allowed.

The advantage that the use of a calculator gives on this particular task makes it unattractive for an online version of the experiment. The alternative task that we use here is to find the two numbers that add up to 100 in a $3 \times 3$ matrix of 9 two-digit numbers (see Figure 1). There were three rounds of two minutes, during which participants could solve as many matrices as possible. One of the three rounds was randomly chosen for payment ex post. Before the start of the three

\footnotetext{
${ }^{7}$ The exact phrasing reads as follows: "Imagine the following hypothetical scenario. You participate in an experiment where you are paid for your performance in a simple task. This task consists in adding up sets of five two-digit numbers without the help of a calculator (so, for example, $43+82+11+94+68=$ ?). You have five minutes to solve as many problems of this type as you can. You have to choose how you want to be paid for your performance in this task: Option 1: Piece rate: you receive 1 Euro for each correctly solved problem; Option 2: Competition: you compete against 3 other people. If you perform better than all three, you receive 4 Euros per correctly solved problem, otherwise you receive nothing. Your three opponents will be randomly selected among the other participants of the LISS panel. Which option would you choose?"

${ }^{8}$ This question was phrased as follows: "In the described task (adding up sets of five two-digit numbers) how well do you think you would perform compared to other participants? In particular, compared to 10 randomly selected LISS panel members, do you think you would come 1st, 2nd, 3rd, .., 10th?"

${ }^{9}$ Moreover, in regressions of both survey measures on outcomes, the coefficient of general competitiveness is typically unaffected by the inclusion of hypothetical competitiveness whereas the coefficient of hypothetical competitiveness often becomes smaller and sometimes insignificant after the inclusion of general competitiveness.
} 
Figure 1: Example matrix task (choice experiment)

\begin{tabular}{|l|l|l|}
\hline$\square 4$ & $\bigcirc 64$ & $\square 59$ \\
\hline 52 & $\bigcirc 44$ & $\bigcirc 23$ \\
\hline 88 & $\square 40$ & $\square 41$ \\
\hline
\end{tabular}

rounds, participants had to correctly solve three practice matrices. At the start of each round, they were informed how they would be paid if that round were to be randomly chosen for payment:

1. Participants receive 40 cents per correctly solved matrix (piece rate).

2. Participants receive 80 per correctly solved matrix if their score is higher than the score of a randomly chosen other participant and zero if their score is lower ${ }^{10}$ (tournament).

3. Participants have to choose between the piece-rate and tournament schemes. If they choose the tournament, their score is compared to the score of a randomly selected other participant. That other participant is chosen among all participants regardless of the payment scheme they chose.

The third-round choice is, conditional on performance in rounds 1 and 2, our incentivized measure of competitiveness. To measure confidence on the task, we asked how well, on a scale from 0 (the worst) to 10 (the best), participants thought they performed compared to other participants. We also asked what they thought their chance was of beating a randomly selected opponent. ${ }^{11}$ The two confidence measures are very highly correlated. To measure risk attitudes, we again included the validated risk question of Dohmen et al. (2011).

In April 2018, we ran this incentivized choice experiment on a subsample of the LISS population. The sample frame was a random selection of participants below 65 years of age who filled in the previous questionnaire. ${ }^{12}$ For most of the analyses, we restrict the sample to participants who are between 25 and 65 years old (and who have presumably finished their education). 2098 individuals participated in the choice experiment. Due to a programming error on the part of LISS, the program crashed halfway the choice experiment for 418 participants. Another six participants quit the experiment before choosing a payment scheme. This leaves us with 1674 observations. Among these, 1437 are between 25 and 65 years old. In Section 2.4, we will show that these individuals do not differ significantly from the other members of the panel in the same age range who participated in the survey one year earlier. They are also not different from the participants who experienced the error.

\footnotetext{
${ }^{10}$ And 40 cents per correct answer in case of a tie.

${ }^{11} \mathrm{On}$ a scale from 0 (the lowest) to 10 (the highest).

${ }^{12}$ We excluded 312 individuals who participated in a small-scale competition experiment run in 2014 (Buser, Plug, and Geijtenbeek, 2018).
} 


\subsection{Measures of career outcomes and other individual traits}

The LISS datasets contain thousands of variables. We concentrate on four education and labor market outcomes: how much people earn, the level of their occupation, their education level, and, in case they went to college, which major they chose. Participants are asked about their gross monthly income every time they answer a questionnaire. We use the measure that was collected in the same wave as our questionnaire measures. ${ }^{13}$

Occupation level is based on the answer to the question "What is your current profession ?". ${ }^{14}$ We divide the answers into the following levels ${ }^{15}$ :

1. Higher academic or independent profession (e.g. architect, physician, scholar, academic instructor, engineer)

2. Higher supervisory profession (e.g. manager, director, owner of large company, supervisory civil servant)

3. Intermediate academic or independent profession (e.g. teacher, artist, nurse, social worker, policy assistant)

4. Intermediate supervisory or commercial profession (e.g. head representative, department manager, shopkeeper)

5. Other mental work (e.g. administrative assistant, accountant, sales assistant, family carer)

6. Skilled manual (e.g. car mechanic, foreman, electrician) or semi-skilled manual (e.g. driver, factory worker)

7. Unskilled (e.g. cleaner, packer) or agrarian (e.g. farm worker)

For some analyses, we group 1 and 2 into a single "high level" category which we use as a binary outcome measure. The question is asked on a yearly basis as part of the "Work and Schooling" core questionnaire. If available, we use the most recent measure from 2017. If a participant did not answer the questionnaire in 2017, we use the information from 2016.

Highest completed level of education is elicited every time somebody answers a questionnaire and is measured in the following categories $^{16}$ :

1. Primary schooling

2. Pre-vocational education

3. Vocational education

4. Upper (pre-college) tracks of secondary school

${ }^{13}$ If a panel member does not enter their gross income but reports their net income, then gross income is imputed based on net income and other variables. See https://www.dataarchive.lissdata.nl/study_units/view/322.

${ }^{14} \mathrm{Or}$, in case a participant was currently not working, "What profession did you exercise in your last job?"

${ }^{15}$ Category 6 combines the answer options "Skilled and supervisory manual work (e.g. car mechanic, foreman, electrician)" and "Semi-skilled manual work (e.g. driver, factory worker)". Category 7 combines the answer options "Unskilled and trained manual work (e.g. cleaner, packer)" and "Agrarian profession (e.g. farm worker, independent agriculturalist)".

${ }^{16}$ In Dutch, these correspond to 1 basisonderwijs, 2 vmbo, 3 mbo, 4 havo/vwo, 5 hbo, 6 wo. 
5. University of applied sciences

6. University

For some analyses, we group 5 and 6 into a single "college" category which we use as a binary measure.

For those who completed college, we divide their field of study into the following categories based on the question "In what field did you complete your highest level of education?"

1. Nursing

2. Humanities and art

3. Social and behavioral sciences

4. Economics and business

5. Law

6. STEM

7. Medicine

The fields are ordered based on the average income of individuals above age 45 in our sample who have completed college in that field. We use this ordering in some of our analyses to see whether competitive individuals choose study majors with better career prospects. The question is asked on a yearly basis as part of the "Work and Schooling" core questionnaire. If available, we use the most recent measure from 2017. If a participant did not answer the questionnaire in 2017, we use information from $2016 .^{17}$

The "Personality" core module contains a 50-question elicitation of the big five personality traits: extroversion, agreeableness, conscientiousness, stability and intellectual openness (Goldberg et al., 2006). From the same module, we use the answer to the question "I have confidence in my capabilities" ( $1=$ totally disagree to $7=$ totally agree) as a measure of general confidence. We also use the results from the 10-item Rosenberg self-esteem scale (Rosenberg, 1965), where each item is scored on a seven point scale $(1=$ totally disagree to $7=$ totally agree). If available, we use information from the 2017 personality questionnaire. If a participant did not answer that questionnaire, we use personality traits measured in $2014 .^{18}$

\footnotetext{
${ }^{17}$ When answering the question, respondents can pick one or several out of the following: 1 . General or no specific field, 2. Teacher training or education, 3. Art, 4. Humanities, 5. Social and behavioral studies, 6. Economics, management, business administration, accountancy, 7. Law, public administration, 8. Mathematics, physics, IT, 9. Technology, 10. Agriculture, forestry, environment, 11. Medical, health services, nursing, etc., 12. Personal care services, 13. Catering, recreation, 14. Transport, logistics, 15. Telecommunication, 16. Public order and safety. We drop respondents who choose 1 and ignore categories 10,12,13,14, 15 and 16 which do not correspond clearly to any college major. We group 1, 2 and 3 into Humanities and Art and 8 and 9 into STEM. We split individuals who answer 11 into Medicine and Nursing, depending on whether they attend a university (which offer only medicine) or university of applied sciences (which offer only nursing). We drop participants who fit more than one category from our major-related analyses.

${ }^{18}$ The Personality module was not collected in 2016. In 2015, only participants who did not answer the big five questions in 2014 received the full big five questionnaire.
} 


\subsection{Descriptive statistics}

Table 1 shows the means and standard deviations of the competitiveness measures as well as of the LISS panel variables we use as controls and as education and labor market outcomes. The first column reports this for the panel members who participated in the choice experiment, the second column for respondents of the unincentivized survey questions. The samples are restricted to individuals between 25 and 65 years old, which is the sample we use for our analyses of the relationship between competitiveness and career outcomes. Around 40 percent of this group has a college degree, around 17 percent holds a high-level occupation and their average gross monthly income amounts to 2480 Euros.

The subsample who participated in the incentivized choice experiment was randomly selected from those who had answered the questionnaire a year earlier. Because not everybody who was selected participated, we check whether the participants in the experiment differ in any way from the rest of the sample. The third column of the table shows that these differences are small and not significantly different from zero, with the exception of the proportion who completed a college degree which is slightly (and marginally significantly) higher in the full sample compared to the experimental sample. In column 4 , we check whether the participants who were affected by the software error differ from the majority of participants who were able to complete the experiment. The differences are small and insignificant in all cases, indicating that the occurrence of the error is essentially random and should not influence any of our conclusions.

Slightly over 27 percent of the participants in the choice experiment opted for the tournament payment instead of the piece rate. This share is lower than the shares typically reported in lab experiments using student populations, but very similar to the 28 percent found for the math task by Boschini et al. (2019) in their telephone interviews. The mean response to the general competitiveness question equals 6.2. Figure 2 shows the entire distribution of this variable. Fortysix percent of the respondents score themselves below a 7 , which is the median value.

Table A1 in the Appendix shows the correlations between the various trait measures for the experimental sample as well as the sample as a whole. Competitiveness is positively correlated with the confidence measures, risk seeking, extroversion, conscientiousness, stability and intellectual openness. The correlations between competitiveness and the big 5 personality traits are stronger for our questionnaire measure than for our binary incentivized measure. The strongest correlation we find is between competitiveness and extroversion. We will take a closer look at the correlation between our incentivized and unincentivized competitiveness measures in Section 3.2.

\section{Results}

We present the results from our analyses in five parts. The first part shows that the incentivized competitiveness measure is a significant and relevant predictor of education and labor market 
Table 1: Descriptive statistics (age between 25 and 65)

\begin{tabular}{|c|c|c|c|c|c|}
\hline & Scale & $\begin{array}{l}\text { Experimental sample } \\
\qquad(1)\end{array}$ & $\begin{array}{c}\text { Full sample } \\
(2) \\
\end{array}$ & $\begin{array}{c}\text { Dif. with } \\
\text { non-participants } \\
(3) \\
\end{array}$ & $\begin{array}{l}\text { Dif. with those } \\
\text { affected by error } \\
(4)\end{array}$ \\
\hline \multicolumn{6}{|c|}{ Experimental questionnaire (2018): } \\
\hline Compete (exp) & $0-1$ & $\begin{array}{c}0.274 \\
(0.446)\end{array}$ & & & \\
\hline Confidence (exp) & $0-10$ & $\begin{array}{c}4.714 \\
(1.927)\end{array}$ & & & \\
\hline Score 1 (exp) & $1-27$ & $\begin{array}{c}8.855 \\
(4.260)\end{array}$ & & & \\
\hline Score 2 (exp) & $1-28$ & $\begin{array}{c}9.620 \\
(4.181)\end{array}$ & & & \\
\hline \multicolumn{6}{|c|}{ Questionnaire (2017): } \\
\hline Competitiveness & $0-10$ & $\begin{array}{c}6.209 \\
(2.066)\end{array}$ & $\begin{array}{c}6.211 \\
(2.038)\end{array}$ & $\begin{array}{c}0.002 \\
(0.074)\end{array}$ & $\begin{array}{c}0.041 \\
(0.118)\end{array}$ \\
\hline Risk seeking & $0-10$ & $\begin{array}{l}5.239 \\
(2.067)\end{array}$ & $\begin{array}{l}5.230 \\
(2.063)\end{array}$ & $\begin{array}{l}-0.016 \\
(0.075)\end{array}$ & $\begin{array}{l}0.118 \\
(0.120)\end{array}$ \\
\hline Confidence (hyp) & $1-10$ & $\begin{array}{c}5.327 \\
(2.054)\end{array}$ & $\begin{array}{l}5.369 \\
(2.021) \\
\end{array}$ & $\begin{array}{c}0.078 \\
(0.073)\end{array}$ & $\begin{array}{l}-0.166 \\
(0.118)\end{array}$ \\
\hline \multicolumn{6}{|c|}{ LISS control variables: } \\
\hline Confidence (gen) & $1-7$ & $\begin{array}{c}5.515 \\
(1.129)\end{array}$ & $\begin{array}{c}5.505 \\
(1.135)\end{array}$ & $\begin{array}{l}-0.019 \\
(0.041)\end{array}$ & $\begin{array}{c}0.118 \\
(0.066)\end{array}$ \\
\hline Extroversion & $1-5$ & $\begin{array}{c}3.203 \\
(0.707)\end{array}$ & $\begin{array}{c}3.220 \\
(0.695)\end{array}$ & $\begin{array}{c}0.033 \\
(0.025)\end{array}$ & $\begin{array}{l}-0.054 \\
(0.040)\end{array}$ \\
\hline Agreeableness & $1-5$ & $\begin{array}{c}3.853 \\
(0.546)\end{array}$ & $\begin{array}{c}3.860 \\
(0.537)\end{array}$ & $\begin{array}{l}0.013 \\
(0.019)\end{array}$ & $\begin{array}{l}-0.018 \\
(0.031)\end{array}$ \\
\hline Conscientiousness & $1-5$ & $\begin{array}{c}3.766 \\
(0.516)\end{array}$ & $\begin{array}{c}3.757 \\
(0.521)\end{array}$ & $\begin{array}{l}-0.016 \\
(0.019)\end{array}$ & $\begin{array}{c}0.001 \\
(0.030)\end{array}$ \\
\hline Stability & $1-5$ & $\begin{array}{c}3.476 \\
(0.736)\end{array}$ & $\begin{array}{c}3.455 \\
(0.729)\end{array}$ & $\begin{array}{l}-0.040 \\
(0.026)\end{array}$ & $\begin{array}{c}0.027 \\
(0.042)\end{array}$ \\
\hline Intellectual openness & $1-5$ & $\begin{array}{c}3.522 \\
(0.518)\end{array}$ & $\begin{array}{c}3.526 \\
(0.509)\end{array}$ & $\begin{array}{c}0.007 \\
(0.018)\end{array}$ & $\begin{array}{c}0.025 \\
(0.030)\end{array}$ \\
\hline Self esteem & $1-7$ & $\begin{array}{c}5.566 \\
(1.036)\end{array}$ & $\begin{array}{c}5.555 \\
(1.054)\end{array}$ & $\begin{array}{l}-0.020 \\
(0.038)\end{array}$ & $\begin{array}{c}0.069 \\
(0.061)\end{array}$ \\
\hline Age & $26-64$ & $\begin{array}{c}47.7 \\
(11.328)\end{array}$ & $\begin{array}{c}47.4 \\
(11.088)\end{array}$ & $\begin{array}{l}-0.607 \\
(0.401)\end{array}$ & $\begin{array}{l}-1.229 \\
(0.641)\end{array}$ \\
\hline Female & Binary & $\begin{array}{c}0.532 \\
(0.499) \\
\end{array}$ & $\begin{array}{c}0.543 \\
(0.498) \\
\end{array}$ & $\begin{array}{c}0.021 \\
(0.018)\end{array}$ & $\begin{array}{l}-0.037 \\
(0.029)\end{array}$ \\
\hline \multicolumn{6}{|c|}{ LISS outcome variables: } \\
\hline Gross monthly income & $0-19,960$ & $\begin{array}{c}2456 \\
(1790)\end{array}$ & $\begin{array}{c}2480 \\
(1766)\end{array}$ & $\begin{array}{c}44.6 \\
(65.9)\end{array}$ & $\begin{array}{c}55.0 \\
(105.8)\end{array}$ \\
\hline Occupation level & $1-7$ & $\begin{array}{c}3.754 \\
(1.626)\end{array}$ & $\begin{array}{c}3.809 \\
(1.623)\end{array}$ & $\begin{array}{c}0.104 \\
(0.060)\end{array}$ & $\begin{array}{c}0.015 \\
(0.095)\end{array}$ \\
\hline High-level occupation & $0-1$ & $\begin{array}{c}0.162 \\
(0.369)\end{array}$ & $\begin{array}{c}0.172 \\
(0.377)\end{array}$ & $\begin{array}{l}0.018 \\
(0.014)\end{array}$ & $\begin{array}{c}0.011 \\
(0.021)\end{array}$ \\
\hline Education level & $1-6$ & $\begin{array}{c}3.739 \\
(1.435)\end{array}$ & $\begin{array}{c}3.791 \\
(1.451)\end{array}$ & $\begin{array}{c}0.096 \\
(0.052)\end{array}$ & $\begin{array}{c}0.042 \\
(0.083)\end{array}$ \\
\hline College & $0-1$ & $\begin{array}{c}0.392 \\
(0.488)\end{array}$ & $\begin{array}{c}0.411 \\
(0.492)\end{array}$ & $\begin{array}{c}0.035 \\
(0.018)\end{array}$ & $\begin{array}{c}0.003 \\
(0.028)\end{array}$ \\
\hline College major rank & $1-7$ & $\begin{array}{c}3.591 \\
(1.742)\end{array}$ & $\begin{array}{c}3.568 \\
(1.748)\end{array}$ & $\begin{array}{l}-0.042 \\
(0.111)\end{array}$ & $\begin{array}{c}0.156 \\
(0.186) \\
\end{array}$ \\
\hline
\end{tabular}

Note: Columns (1) and (2) report means, with standard deviations in parentheses, for the experimental sample and the full sample, respectively. Column (3) reports differences, with standard errors in parentheses, between the experimental sample and respondents who are in the full sample but not in the experimental sample. Column (4) reports differences, with standard errors in parentheses, between the experimental sample and respondents who were supposed to participate in the experiment but encountered a software error that prevented them from doing so. Score 1 (2) is the number of correct answers in the first (second) round of the experiment. All other variables are described in the text. 
Figure 2: Distribution of responses to general competitiveness question

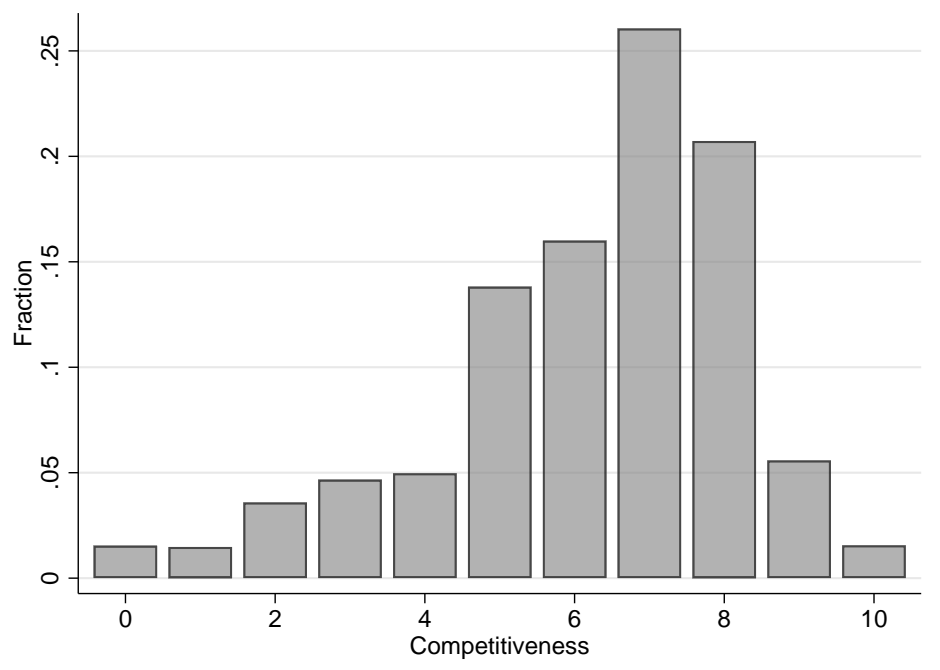

outcomes in a representative sample of the Dutch working-age population. In the second part, we show that our unincentivized questionnaire measure predicts the same outcomes with similar predictive power and is often a stronger predictor of these outcomes compared to the other nonincentivized trait measures (risk seeking, confidence and the big five personality traits). In the third part, we provide further evidence that competitiveness and risk seeking are two distinct traits which predict different outcomes. In the fourth part, we explore association between competitiveness on the one hand and personal wellbeing and social orientation on the other hand. In the fifth part, we look at the gender difference in competitiveness and show that it can explain a moderate but meaningful part of gender differences in education and labor market outcomes.

\subsection{Incentivized measure of competitiveness}

Figure 3 shows how respondents who chose the tournament option and respondents who chose the piece-rate option are distributed across different levels of each of the four education and labor market variables. In the two upper-most panels, we divide the sample into income quintiles. Because the income distributions of men and women are very different, we do this separately by gender. For each gender, the income distributions of individuals who chose to compete and individuals who chose not to compete differ strongly. Individuals who compete are more than twice as likely to be in the highest quintile and much less likely to be in lowest two quintiles.

In the center panel, we graph the distribution of occupational level by competitiveness. Individuals who compete are around three times as likely to work in a high academic or independent position and more than two times as likely to work in a high supervisory position compared to individuals who do not compete. Individuals who do not compete are more likely to work in non-academic and non-supervisory occupations.

In the two lower panels, we look at educational outcomes. In the lower-left panel, we split the 
Figure 3: Experimentally measured competitiveness and career outcomes
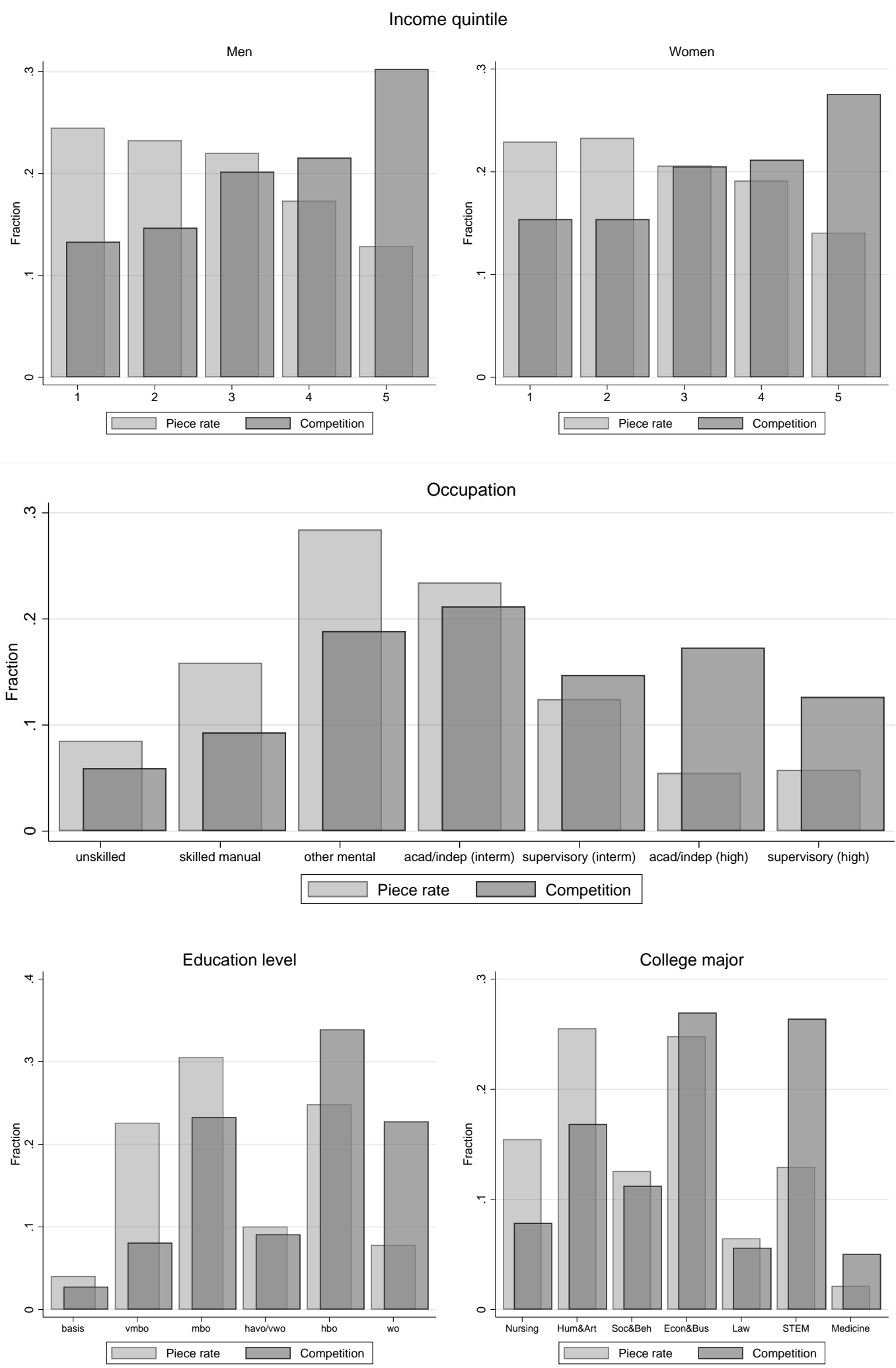

Note: the figures show the distribution of participants across different values of our outcome variables separately for participants who chose who chose competition in the online experiment and participants who chose the piece rate payment in the online experiment. The classifications of occupational levels, education levels and college majors are explained in Section 2.3. 
sample by education level. Individuals who compete are more highly educated on average than non-competing individuals, being three times as likely to have graduated from university (wo) and 36 percent more likely to have graduated from a university of applied sciences (hbo). In the lower-right panel, we look at the choice of college major for individuals with a college (university or university of applied sciences) degree. In the graph, majors are ordered according to the average income of individuals over 45 years of age in our sample who graduated from that major. College graduates who chose competition are more than twice as likely to have graduated from one of the two highest paying majors (medicine or STEM) and about 40 percent less likely to have graduated from one of the two lowest paying majors (nursing or humanities and art).

In Table 2, we examine the robustness of the predictive power of the incentivized measure for these career outcomes to the inclusion of controls for performance in the experimental task, gender, age, risk seeking, confidence, and the big five personality traits. In each regression, we limit the sample to individuals for whom we have both the outcome variable as well as all the control variables. The number of observations fluctuates slightly across outcomes because not all outcome variables are available for all participants. The sample is much smaller for the regressions using college major as the outcome variable because they include only participants with a college degree.

Panels A to D report results from regressions of monthly gross income on incentivized competitiveness. In Panel A, we use a simple OLS regression. ${ }^{19}$ Conditional on performance in the task, gender and age, individuals who compete in the experiment earn 550 Euros more per month (relative to an average monthly income of 2205 Euros for individuals who do not compete). Additionally controlling for the big five personality traits, risk attitudes and confidence hardly changes the estimate: competitive individuals still earn 470 Euros more. Additionally controlling for education level dummies, the difference is 290 Euros. This indicates that part of the relationship between competitiveness and income is due to a relationship between competitiveness and level of education

In order to deal with outliers and to investigate the predictive power of competitiveness at different parts of the income distribution, we use quantile regressions in Panels B, C and D (20th percentile, median and 80th percentile respectively). Conditional on the other traits, the competition coefficient is equal to 585 Euros at the 80th percentile, 382 Euros at the median and 443 Euros at the 20th percentile. Conditional on education level, the coefficient is significant and similar at all three levels, fluctuating between 280 and 310 Euros, indicating that for those who compete, the entire income distribution is shifted to the right.

We use two methods to analyze the predictive power of incentivized competitiveness for occupational position. First, we use OLS to regress a dummy indicating that an individual holds

\footnotetext{
${ }^{19}$ We do not think that the common strategy of using log income is appropriate here because it eliminates zeroearners from the sample, who, in our case, are disproportionally women. It also puts disproportionate weight on differences occurring at the lower end of the income distribution, rather than the upper end where we would expect the strongest effects of competitiveness.
} 
Table 2: Career outcomes and incentivized competitiveness

\begin{tabular}{|c|c|c|c|c|c|c|c|}
\hline & $(1)$ & $(2)$ & $(3)$ & $(4)$ & $(5)$ & $(6)$ & $(7)$ \\
\hline \multicolumn{8}{|c|}{ A. Monthly gross income (OLS) } \\
\hline Compete & $\begin{array}{l}717.3^{* * *} \\
(116.1)\end{array}$ & $\begin{array}{c}549.4^{* * *} \\
(106.7)\end{array}$ & $\begin{array}{c}469.4^{* * *} \\
(100.6)\end{array}$ & $\begin{array}{c}469.1^{* * *} \\
(103.1)\end{array}$ & $\begin{array}{c}301.9^{* * *} \\
(95.6)\end{array}$ & $\begin{array}{c}270.1^{* * *} \\
(93.1)\end{array}$ & $\begin{array}{c}289.2^{* * *} \\
(96.0)\end{array}$ \\
\hline $\mathrm{N}$ & 1326 & 1326 & 1326 & 1326 & 1326 & 1326 & 1326 \\
\hline adj. R-sq & 0.074 & 0.240 & 0.275 & 0.280 & 0.350 & 0.363 & 0.368 \\
\hline \multicolumn{8}{|c|}{ B. Monthly gross income (quantile regression: 20th decile) } \\
\hline \multirow[t]{2}{*}{ Compete } & $\begin{array}{l}572.1^{* * *} \\
(148.8)\end{array}$ & $\begin{array}{c}397.7^{* * *} \\
(107.3)\end{array}$ & $\begin{array}{c}443.0^{* * *} \\
(107.8)\end{array}$ & $\begin{array}{c}436.4^{* * *} \\
(102.1)\end{array}$ & $\begin{array}{c}312.1^{* * *} \\
(116.5)\end{array}$ & $\begin{array}{c}233.0^{* *} \\
(110.8)\end{array}$ & $\begin{array}{c}309.6^{* * *} \\
(110.3)\end{array}$ \\
\hline & 1326 & 1326 & 1326 & 1326 & 1326 & 1326 & 1326 \\
\hline \multicolumn{8}{|c|}{ C. Monthly gross income (quantile regression: median) } \\
\hline \multirow[t]{2}{*}{ Compete } & $\begin{array}{l}521.7^{* * *} \\
(119.4)\end{array}$ & $\begin{array}{c}501.0^{* * *} \\
(99.7)\end{array}$ & $\begin{array}{c}382.2^{* * *} \\
(102.9)\end{array}$ & $\begin{array}{c}351.6^{* * *} \\
(102.4)\end{array}$ & $\begin{array}{c}231.2^{* * * *} \\
(85.5)\end{array}$ & $\begin{array}{c}255.2^{* * *} \\
(83.3)\end{array}$ & $\begin{array}{c}282.9^{* * *} \\
(92.0)\end{array}$ \\
\hline & 1326 & 1326 & 1326 & 1326 & 1326 & 1326 & 1326 \\
\hline \multicolumn{8}{|c|}{ D. Monthly gross income (quantile regression: 80th decile) } \\
\hline \multirow[t]{2}{*}{ Compete } & $\begin{array}{l}897.9^{* * *} \\
(158.4)\end{array}$ & $\begin{array}{c}772.9^{* * *} \\
(140.2)\end{array}$ & $\begin{array}{c}585.2^{* * *} \\
(125.3)\end{array}$ & $\begin{array}{c}580.0^{* * *} \\
(132.9)\end{array}$ & $\begin{array}{c}323.1^{* *} \\
(131.1)\end{array}$ & $\begin{array}{c}343.7^{* * *} \\
(122.9)\end{array}$ & $\begin{array}{c}283.4^{* *} \\
(134.0)\end{array}$ \\
\hline & 1326 & 1326 & 1326 & 1326 & 1326 & 1326 & 1326 \\
\hline \multicolumn{8}{|c|}{ E. High-level professional or managerial position (OLS) } \\
\hline Compete & $\begin{array}{l}0.157^{* * *} \\
(0.026)\end{array}$ & $\begin{array}{c}0.144^{* * *} \\
(0.026)\end{array}$ & $\begin{array}{c}0.123^{* * *} \\
(0.025)\end{array}$ & $\begin{array}{c}0.119^{* * *} \\
(0.025)\end{array}$ & $\begin{array}{c}0.066^{* * *} \\
(0.023)\end{array}$ & $\begin{array}{c}0.060^{* * *} \\
(0.023)\end{array}$ & $\begin{array}{c}0.062^{* * *} \\
(0.023)\end{array}$ \\
\hline $\mathrm{N}$ & 1386 & 1386 & 1386 & 1386 & 1386 & 1386 & 1386 \\
\hline adj. R-sq & 0.061 & 0.074 & 0.126 & 0.126 & 0.287 & 0.299 & 0.297 \\
\hline \multicolumn{8}{|c|}{ F. Occupation (ordered probit) } \\
\hline Compete & $\begin{array}{l}0.378^{* * *} \\
(0.067)\end{array}$ & $\begin{array}{c}0.366^{* * *} \\
(0.069)\end{array}$ & $\begin{array}{c}0.310^{* * * *} \\
(0.069)\end{array}$ & $\begin{array}{c}0.305^{* * *} \\
(0.070)\end{array}$ & $\begin{array}{c}0.166^{* *} \\
(0.068) \\
\end{array}$ & $\begin{array}{c}0.147^{* *} \\
(0.069)\end{array}$ & $\begin{array}{c}0.156^{* *} \\
(0.070)\end{array}$ \\
\hline$\overline{\mathrm{N}}$ & 1386 & 1386 & 1386 & 1386 & 1386 & 1386 & 1386 \\
\hline \multicolumn{8}{|l|}{ G. College (OLS) } \\
\hline Compete & $\begin{array}{l}0.185^{* * *} \\
(0.030)\end{array}$ & $\begin{array}{c}0.172^{* * *} \\
(0.030)\end{array}$ & $\begin{array}{c}0.142^{* * *} \\
(0.029)\end{array}$ & $\begin{array}{c}0.133^{* * *} \\
(0.029)\end{array}$ & & & \\
\hline $\mathrm{N}$ & 1409 & 1409 & 1409 & 1409 & & & \\
\hline adj. R-sq & 0.080 & 0.110 & 0.182 & 0.188 & & & \\
\hline \multicolumn{8}{|c|}{ H. Education level (ordered probit) } \\
\hline Compete & $\begin{array}{l}0.466^{* * *} \\
(0.068)\end{array}$ & $\begin{array}{c}0.438^{* * *} * \\
(0.068)\end{array}$ & $\begin{array}{c}0.388^{* * *} \\
(0.068)\end{array}$ & $\begin{array}{c}0.352^{* * *} \\
(0.069)\end{array}$ & & & \\
\hline $\mathrm{N}$ & 1409 & 1409 & 1409 & 1409 & & & \\
\hline \multicolumn{8}{|c|}{ I. College major (ordered probit) } \\
\hline Compete & $\begin{array}{l}0.372^{* * *} \\
(0.103)\end{array}$ & $\begin{array}{c}0.235^{* *} \\
(0.104)\end{array}$ & $\begin{array}{c}0.248^{* *} \\
(0.105)\end{array}$ & $\begin{array}{c}0.169 \\
(0.108)\end{array}$ & & & \\
\hline $\mathrm{N}$ & 449 & 449 & 449 & 449 & & & \\
\hline Score & $\sqrt{ }$ & $\sqrt{ }$ & $\sqrt{ }$ & $\sqrt{ }$ & $\sqrt{ }$ & $\sqrt{ }$ & $\sqrt{ }$ \\
\hline Gender, age & & $\sqrt{ }$ & $\sqrt{ }$ & $\sqrt{ }$ & $\sqrt{ }$ & $\sqrt{ }$ & $\sqrt{ }$ \\
\hline Education level & & & & & $\sqrt{ }$ & $\sqrt{ }$ & $\sqrt{ }$ \\
\hline Big 5 & & & $\sqrt{ }$ & $\sqrt{ }$ & & $\sqrt{ }$ & $\sqrt{ }$ \\
\hline Confidence and risk & & & & $\sqrt{ }$ & & & $\sqrt{ }$ \\
\hline \multicolumn{8}{|c|}{$\begin{array}{l}\text { Note: Each estimate comes from a separate regression of a career outcome on the binary incentivized competition } \\
\text { choice and the control variables indicated in the bottom rows. Score is individuals' performance in the first and } \\
\text { second round of the choice experiment. Education level is measured by dummy variables indicating different levels. } \\
\text { Big } 5 \text { are obtained from the } 50 \text { question elicitation of the big } 5 \text { personality traits: extroversion, agreeableness, } \\
\text { conscientiousness, stability and intellectual openness. Risk attitudes is measured by the Dohmen et al. (2011) } \\
\text { survey measure which we elicited at the same time as our unincentivized measures of competitiveness. We use three } \\
\text { separate measures for confidence: an individual's confidence in their own relative performance in the experimental } \\
\text { task, their Rosenberg's self-esteem scale and their confidence in their own capabilities judged on a seven-point scale. } \\
\text { Standard errors in parentheses. } * / * * * * * \text { indicates significance at the } 10 / 5 / 1 \% \text {-level. }\end{array}$} \\
\hline
\end{tabular}


a high-level academic, independent or supervisory position on incentivized competitiveness and controls. Second, we rank positions according to the ranking laid out in Section 2.3 and use ordered probit regressions. Conditional on performance in the task, gender and age, individuals who compete in the experiment are 14 percentage points more likely to hold a high-level position (a large difference relative to 11 percent for those who choose the piece rate). Again, the estimate hardly changes when controlling for risk seeking, confidence and the big five personality traits (12 percentage points). The coefficient is reduced by roughly half when we control for education level, indicating that the relationship between competitiveness and occupation is partially due to a relationship between competitiveness and education level. The coefficient on incentivized competitiveness is also consistently significant in the ordered probit regressions.

Moving to education level in Panels G and H, we use OLS regressions of a dummy indicating that an individual completed college on incentivized competitiveness and controls, as well as ordered probit regressions using the ordering of educational levels laid out in Section 2.3. Conditional on performance in the task, gender and age, individuals who compete are 17 percentage points more likely to have attended college (relative to 33 percent of individuals who do not compete). The coefficient decreases to 13 percentage points when controlling for the big five traits, risk attitudes and confidence. The ordered probit regressions confirm that competitiveness consistently predicts a higher education level. Finally, for the subsample who have attended college, in Panel I we regress college major (ranked according to the average income of individuals over 45 years of age in our sample who graduated from each major) on incentivized competitiveness using ordered probit. Conditional on performance in the task, gender and age, competing is associated with graduating from a major that is ranked significantly higher. The coefficient is robust to controlling for the big five personality traits, but reduces in size and loses statistical significance when we additionally control for confidence and risk attitudes.

\subsection{Survey measure of competitiveness}

Having shown that the incentivized measure of competitiveness is a strong predictor of outcomes, in this section, we will focus on our unincentivized survey measure. We will validate this measure, which was collected approximately one year prior to the incentivized measure, in two ways. First, we will show that the unincentivized measure predicts the incentivized competition choice that was elicited a year later, a method previously applied by Dohmen et al. (2011) and Falk et al. (2016). Second, we will use the fact that we elicited both the incentivized and the unincentivized measures in the same sample to assess whether the unincentivized measure predicts the same outcomes we analyzed in the previous section for the incentivized measure. ${ }^{20}$

We find that for individuals of working age who participated in our experiment, their incen-

\footnotetext{
${ }^{20}$ See appendix B for results for the second unincentivized measure - respondents' answers to a hypothetical Niederle-Vesterlund tournament entry decision.
} 
tivized choice and their answer to our unincentivized 11-point measure are strongly correlated. The correlation coefficient is equal to $0.153(\mathrm{p}<0.001)$. To properly judge the strength of this correlation, we have to take into account that the experimental measure and the survey measure were elicited one year apart. This is a strength because it rules out spurious correlation due to a desire to be consistent (Falk and Zimmermann, 2013) or other direct effects between the two elicitations, but it also introduces noise due to the passing of time.

One approach to correct for this is to use the test-retest correlation of a related measure across the same time span as benchmark. We elicited the exact same survey measure of risk preferences taken from Dohmen et al. (2011) in both surveys. We can use the correlation between the two answers as a benchmark for the correlation between our incentivized and non-incentivized competitiveness measures. The correlation between the two risk preference answers elicited one year apart is 0.404 . Using this as a benchmark to scale the correlation between the two competitiveness measures leads to a correlation of $0.154 / 0.404=0.380 .^{21}$

In Figure 4, we show the relationship between our survey measure of competitiveness and outcomes, repeating the analysis in Figure 3. To make the graphs comparable, we dichotomize our 11-point measure by splitting the sample into people whose competitiveness is below or above the median. ${ }^{22}$ The unincentivized survey measure is strongly related to income. For both men and women, individuals who are above-median competitive are substantially more likely to be in the highest quintile (86 percent more likely for men and 49 percent for women) and less likely to be in the lowest quintile (28 percent for men and 28 percent for women) than individuals who are below-median competitive. Looking at occupation level, we again find that the results from the incentivized measure replicate quite closely. Individuals who are above-median competitive are around three times as likely to work in a high supervisory position and 60 percent more likely to work in a high academic or independent position. They are also 70 percent more likely to work in an intermediary supervisory position.

Looking at education, above-median competitive individuals are 70 percent more likely to have graduated from a university and 26 percent more likely to have graduated from a university of applied sciences. The unincentivized measure is also related to the choice of college major. As with the incentivized measure, more competitive individuals tend to have graduated from more lucrative majors. Nevertheless, the picture looks slightly different compared to the incentivized choice. When using the incentivized measure, competitive people were much more likely to have

\footnotetext{
${ }^{21}$ The correlation between our second, hypothetical choice measure and the incentivized choice is $0.200(\mathrm{p}<0.001)$. A composite measure created by standardizing and adding up the two survey measures has a correlation of 0.216 $(\mathrm{p}<0.001)$. If we scale these correlations up using the test-retest correlation of the risk preference measure as a benchmark, we get a correlation of 0.495 for the hypothetical choice measure and a correlation of 0.536 for the composite measure. An alternative way to correct for the passing of time is to compare how choosing the tournament option in the experiment is correlated to the contemporaneous risk measure and the risk measure elicited one year before. The contemporaneous correlation is 3.11 times stronger (0.364 versus 0.117$)$. If we use this factor to scale up the correlations between our survey measures and the incentivized competition choice, we get correlations of 0.478 for the 11-point measure, 0.622 for the hypothetical choice measure, and 0.673 for the composite measure.

${ }^{22}$ This splits the sample into individuals with a competitiveness of 0-6 and 7-10
} 
Figure 4: Questionnaire measure of competitiveness and career outcomes
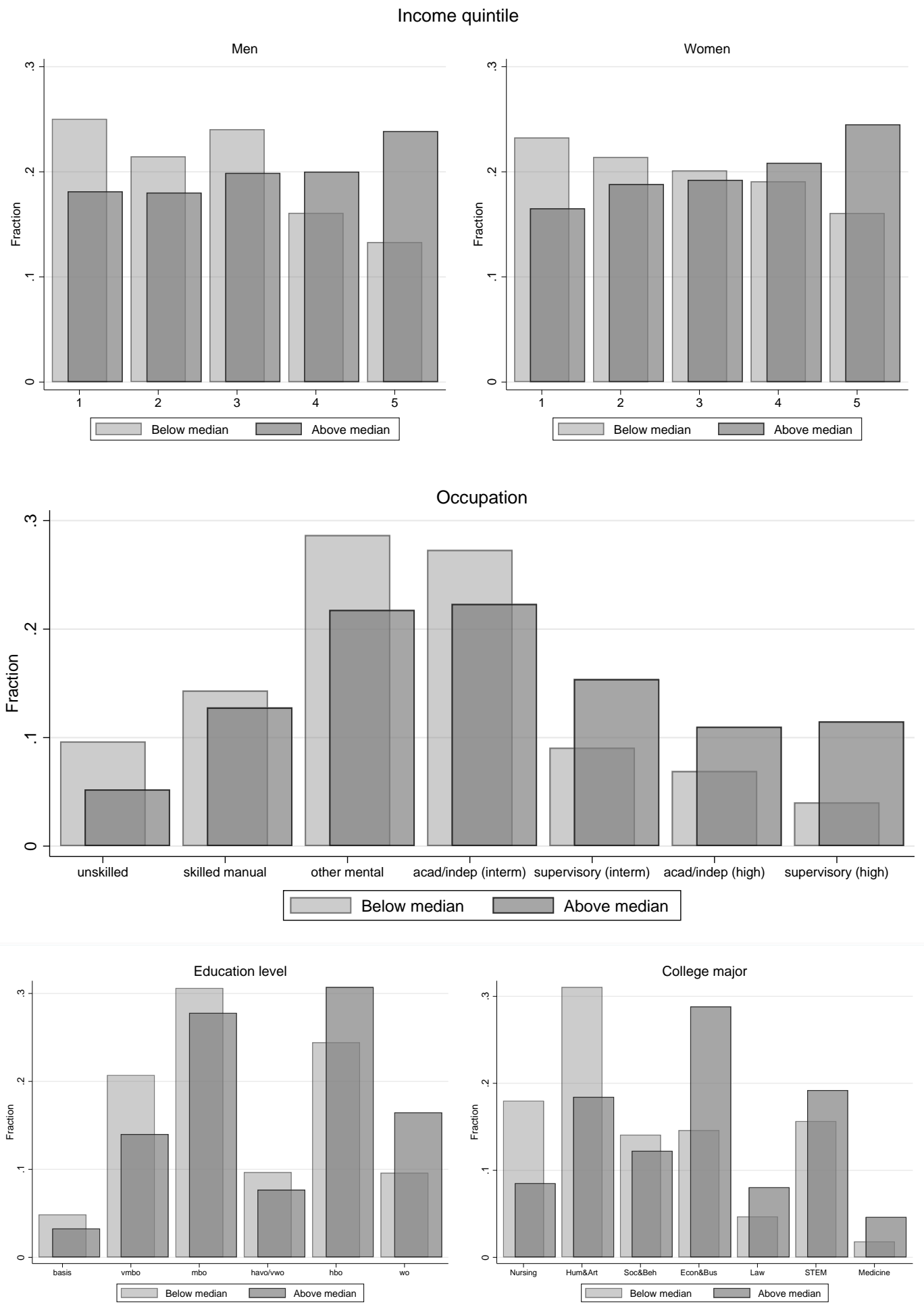

Note: The figures show the distribution of participants across different values of our outcome variables separately for survey respondents who judged themselves to be above-median (7-10) and below-median (0-6) competitive on an 11-point scale. The classifications of occupational levels, education levels and college majors are explained in Section 2.3 . 
chosen medicine or STEM (and less likely to have chosen nursing or humanities and art). Using the unincentivized measure, we again find a much higher likelihood of having a degree in medicine and a much lower likelihood of having a degree in nursing or humanities and art, but we now also find that individuals who judge themselves to be more competitive are about twice as likely to have a degree in economics and business or law (on the other hand, they are only slightly more likely to have a STEM degree). Overall, the graphs indicate that the unincentivized survey measure is related to education and labor market outcomes in ways that are very similar to the patterns observed for the incentivized measure.

In Table 3, we repeat the analysis in Table 2 for the unincentivized survey measure using data from the full working-age sample. Using regressions, we examine whether the predictive power of the survey measure for education and labor market variables is robust to the inclusion of controls for gender, age, risk attitudes, confidence, and the big five personality traits.

The unincentivized survey measure of competitiveness significantly predicts all four outcomes conditional on all mentioned controls. The coefficients are substantial. For instance, panel A, column 2 shows that individuals who judge themselves one point more competitive (on an 11point scale) earn roughly 100 Euros more per month. When we compare this coefficient to the one in panel A, column 2 of Table 2, we see that the effect of choosing competition in the incentivized choice experiment is roughly equivalent to moving up five (out of 11) points on the survey scale. Conditional on gender, age, confidence, risk preference and the big five personality traits, the most competitive people (those who score themselves highest on the 11-point scale) earn 740 Euros more per month, are 14 percentage points more likely to hold a high-level occupation, are 17 percentage points more likely to have gone to college and, conditional on having gone to college, chose a one spot higher-ranked college major compared to the least competitive people.

Having established that our survey measure of competitiveness is a strong and robust predictor of education and labor market outcomes, we now want to compare the predictive power of competitiveness to that of the other traits, namely the big five personality traits, confidence and risk attitudes. These traits are measured on varying scales. To make the effects comparable, we use a method inspired by Heckman, Stixrud, and Urzua (2006). ${ }^{23}$ We use OLS regressions to estimate the effect on the outcome variables of moving from the bottom 30 percent to the top 30 percent on each of the trait variables.

Results are presented in Figure 5. Here, we graph the regression coefficients for each trait controlling for age, gender, education (in the case of income and occupational position), as well as all other traits. That is, the coefficients tell us how predictive a trait is on top of all the other traits. $^{24}$ In Figure A1 in the appendix, we show the effects of moving from the bottom 30 percent

\footnotetext{
${ }^{23}$ In their analysis of the importance of cognitive and noncognitive abilities on labor market outcomes and social behavior, Heckman, Stixrud, and Urzua (2006) calculate what would happen to an outcome if a person's (non)cognitive ability increases from the lowest to the highest decile.

${ }^{24}$ The exception are the two measures of confidence which are supposed to elicit the same underlying trait and where we therefore control for all other traits except the other confidence measure.
} 
Table 3: Career outcomes and questionnaire measure of competitiveness

\begin{tabular}{|c|c|c|c|c|c|c|c|}
\hline & (1) & (2) & (3) & (4) & (5) & (6) & $(7)$ \\
\hline \multicolumn{8}{|c|}{ A. Monthly gross income (OLS) } \\
\hline Competitiveness & $\begin{array}{c}154.1^{* * *} \\
(13.3)\end{array}$ & $\begin{array}{c}98.6^{* * *} \\
(12.6)\end{array}$ & $\begin{array}{c}74.7^{* * *} \\
(12.7)\end{array}$ & $\begin{array}{c}74.1^{* * *} \\
(13.4)\end{array}$ & $\begin{array}{c}74.1^{* * *} \\
(11.5)\end{array}$ & $\begin{array}{c}59.8^{* * *} \\
(11.7)\end{array}$ & $\begin{array}{c}55.9^{* * *} \\
(12.2)\end{array}$ \\
\hline \multirow{2}{*}{$\begin{array}{l}\mathrm{N} \\
\text { adj. R-sq }\end{array}$} & 2886 & 2886 & 2886 & 2886 & 2883 & 2883 & 2883 \\
\hline & 0.042 & 0.217 & 0.253 & 0.257 & 0.373 & 0.386 & 0.389 \\
\hline \multicolumn{8}{|c|}{ income (quantile regression: 20th decile) } \\
\hline \multirow[t]{2}{*}{ Competitiveness } & $\begin{array}{c}141.8^{* * *} \\
(18.8)\end{array}$ & $\begin{array}{c}64.9^{* * *} \\
(19.2)\end{array}$ & $\begin{array}{c}42.5^{* *} \\
(19.7)\end{array}$ & $\begin{array}{c}53.2^{* * *} \\
(18.8)\end{array}$ & $\begin{array}{c}55.2^{* * *} \\
(19.0)\end{array}$ & $\begin{array}{c}28.3 \\
(18.3)\end{array}$ & $\begin{array}{l}33.9^{*} \\
(19.5)\end{array}$ \\
\hline & 2886 & 2886 & 2886 & 2886 & 2883 & 2883 & 2883 \\
\hline \multicolumn{8}{|c|}{ C. Monthly gross income (quantile regression: median) } \\
\hline \multirow[t]{2}{*}{ Competitiveness } & $\begin{array}{c}158.3^{* * *} \\
(16.5)\end{array}$ & $\begin{array}{c}93.5^{* * *} \\
(16.0)\end{array}$ & $\begin{array}{c}65.0^{* * *} \\
(16.8)\end{array}$ & $\begin{array}{c}70.6^{* * *} \\
(18.3)\end{array}$ & $\begin{array}{c}60.7^{* * *} \\
(12.6)\end{array}$ & $\begin{array}{c}52.6^{* * *} \\
(13.1)\end{array}$ & $\begin{array}{c}49.7^{* * *} \\
(14.2)\end{array}$ \\
\hline & 2886 & 2886 & 2886 & 2886 & 2883 & 2883 & 2883 \\
\hline \multicolumn{8}{|c|}{ D. Monthly gross income (quantile regression: 80th decile) } \\
\hline \multirow[t]{2}{*}{ Competitiveness } & $\begin{array}{c}168.0^{* * *} \\
(25.1)\end{array}$ & $\begin{array}{c}128.3^{* * *} \\
(20.7)\end{array}$ & $\begin{array}{c}95.5^{* * *} \\
(23.2)\end{array}$ & $\begin{array}{c}86.5^{* * *} \\
(23.6)\end{array}$ & $\begin{array}{c}86.0^{* * *} \\
(17.8)\end{array}$ & $\begin{array}{c}77.5^{* * *} \\
(18.4)\end{array}$ & $\begin{array}{c}65.8^{* * *} \\
(18.3)\end{array}$ \\
\hline & 2886 & 2886 & 2886 & 2886 & 2883 & 2883 & 2883 \\
\hline \multicolumn{8}{|c|}{ E. High-level professional or managerial position (OLS) } \\
\hline Competitiveness & $\begin{array}{c}0.026^{* * *} \\
(0.003)\end{array}$ & $\begin{array}{c}0.020^{* * *} \\
(0.003)\end{array}$ & $\begin{array}{c}0.013^{* * *} \\
(0.003)\end{array}$ & $\begin{array}{c}0.014^{* * *} \\
(0.003)\end{array}$ & $\begin{array}{c}0.013^{* * *} \\
(0.003)\end{array}$ & $\begin{array}{c}0.010^{* * *} \\
(0.003)\end{array}$ & $\begin{array}{c}0.009^{* * *} \\
(0.003)\end{array}$ \\
\hline $\mathrm{N}$ & 2972 & 2972 & 2972 & 2972 & 2970 & 2970 & 2970 \\
\hline adj. R-sq & 0.020 & 0.043 & 0.098 & 0.097 & 0.286 & 0.292 & 0.292 \\
\hline \multicolumn{8}{|c|}{ F. Occupation (ordered probit) } \\
\hline Competitiveness & $\begin{array}{c}0.080^{* * *} \\
(0.009)\end{array}$ & $\begin{array}{c}0.070^{* * *} * \\
(0.009)\end{array}$ & $\begin{array}{c}0.044^{* * *} \\
(0.010)\end{array}$ & $\begin{array}{c}0.041^{* * *} \\
(0.010)\end{array}$ & $\begin{array}{c}0.056^{* * *} \\
(0.009)\end{array}$ & $\begin{array}{c}0.036^{* * * *} \\
(0.010)\end{array}$ & $\begin{array}{c}0.029^{* * *} \\
(0.010)\end{array}$ \\
\hline $\mathrm{N}$ & 2972 & 2972 & 2972 & 2972 & 2970 & 2970 & 2970 \\
\hline \multicolumn{8}{|c|}{ G. College (OLS) } \\
\hline Competitiveness & $\begin{array}{c}0.029^{* * *} \\
(0.004)\end{array}$ & $\begin{array}{c}0.023^{* * *} \\
(0.004)\end{array}$ & $\begin{array}{c}0.016^{* * *} \\
(0.004)\end{array}$ & $\begin{array}{c}0.017^{* * *} \\
(0.005)\end{array}$ & & & \\
\hline $\mathrm{N}$ & 3079 & 3079 & 3079 & 3079 & & & \\
\hline adj. R-sq & 0.014 & 0.041 & 0.127 & 0.130 & & & \\
\hline
\end{tabular}

\section{H. Education level (ordered probit)}

\begin{tabular}{lcccc} 
Competitiveness & $\begin{array}{c}0.064^{* * *} \\
(0.009)\end{array}$ & $\begin{array}{c}0.044^{* * *} \\
(0.009)\end{array}$ & $\begin{array}{c}0.031^{* * *} \\
(0.010)\end{array}$ & $\begin{array}{c}0.038^{* * *} \\
(0.011)\end{array}$ \\
\hline $\mathrm{N}$ & 3079 & 3079 & 3079 & 3079
\end{tabular}

I. College major (ordered probit)

$\begin{array}{lllll}\text { Competitiveness } & 0.116^{* * *} & 0.072^{* * *} & 0.076^{* * *} & 0.074^{* * *}\end{array}$

\begin{tabular}{lccccccc} 
& $(0.018)$ & $(0.019)$ & $(0.020)$ & $(0.021)$ & & & \\
\hline $\mathrm{N}$ & 1002 & 1002 & 1002 & 1002 & & & \\
\hline Gender, age & & $\sqrt{n}$ & $\sqrt{ }$ & $\sqrt{ }$ & $\sqrt{ }$ & $\sqrt{ }$ & $\sqrt{ }$ \\
Education level & & & $\checkmark$ & $\sqrt{ }$ & & $\sqrt{ }$ & $\sqrt{ }$ \\
Big 5 & & & $\sqrt{ }$ & & & $\sqrt{ }$
\end{tabular}

Note: Each estimate comes from a separate regression of a career outcome on the unincentivized competitiveness variable and the control variables indicated in the bottom rows.Education level is measured by dummy variables indicating different levels. Big 5 are obtained from the 50 question elicitation of the big 5 personality traits: extroversion, agreeableness, conscientiousness, stability and intellectual openness. Risk attitudes is measured by the Dohmen et al. (2011) survey measure which we elicited at the same time as our unincentivized measures of competitiveness. We use two separate measures for confidence: their Rosenberg's self-esteem scale and their confidence in their own capabilities judged on a seven-point scale. Standard errors in parentheses. */**/*** indicates significance at the $10 / 5 / 1 \%$-level. 
Figure 5: Predictive power of individual traits compared: effect of moving from bottom 30 percent to top 30 percent conditional on all other traits

Effect on gross monthly income (cond. on education)
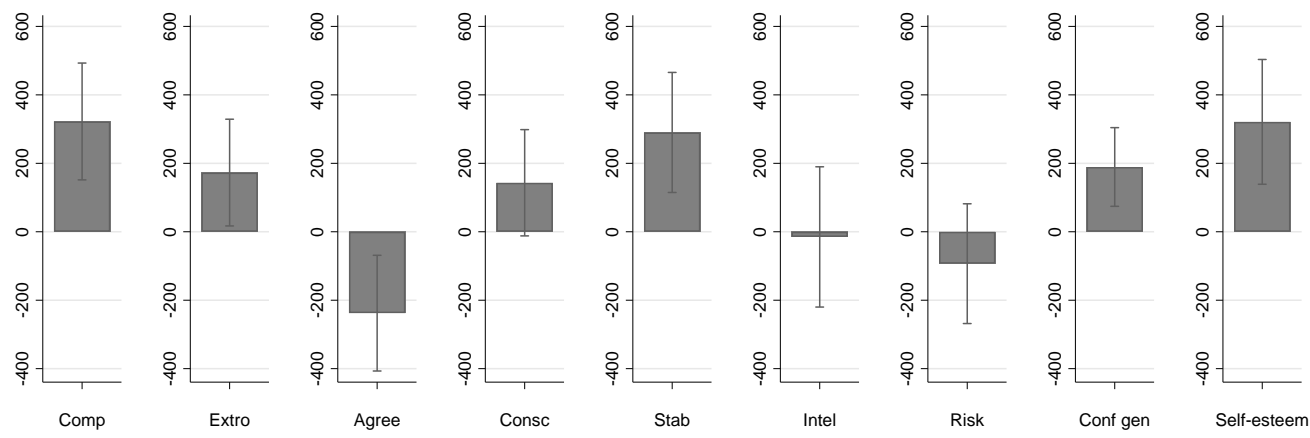

Effect on proportion in high-level professional or managerial position (cond. on education)
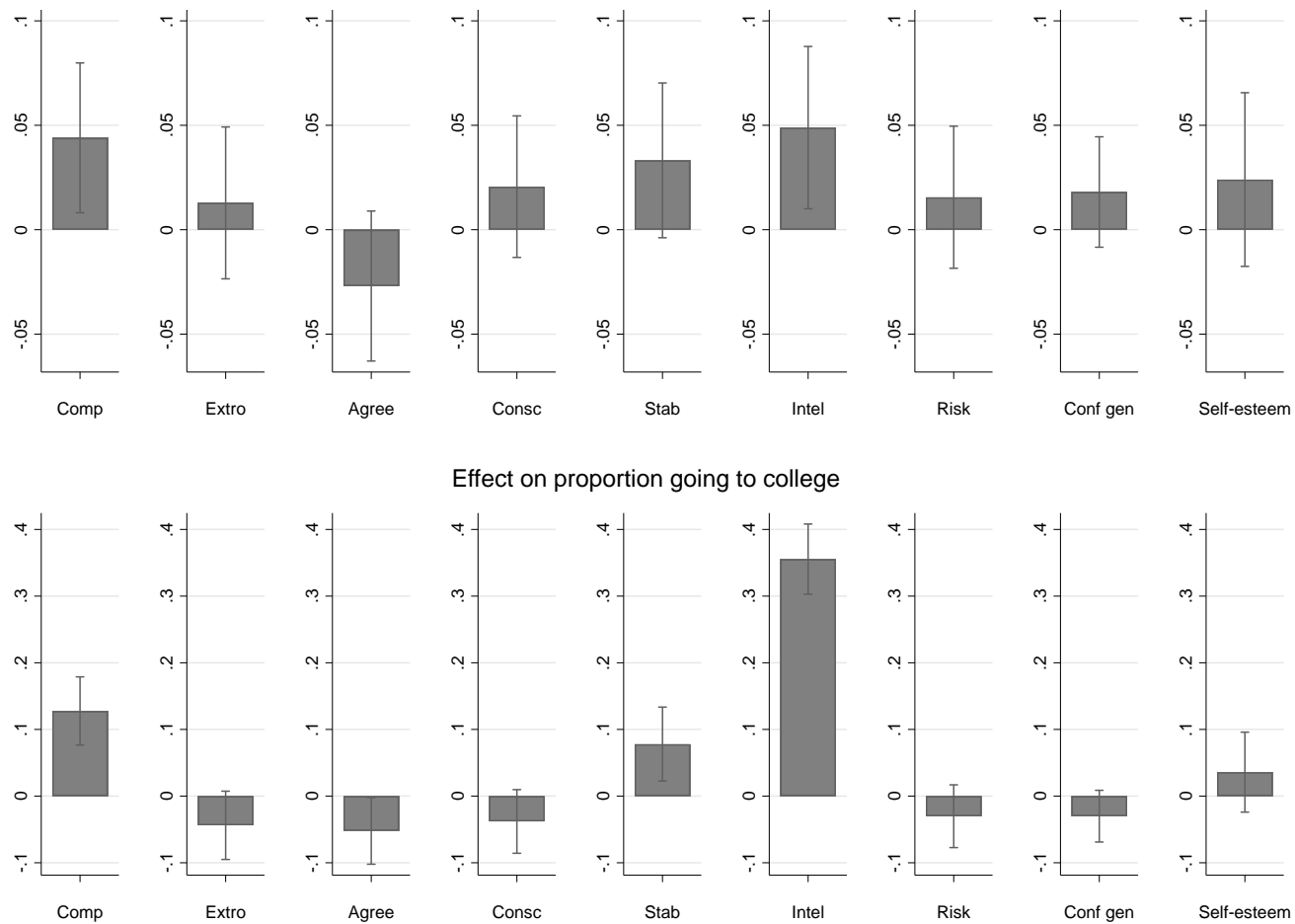

Effect on proportion going to college
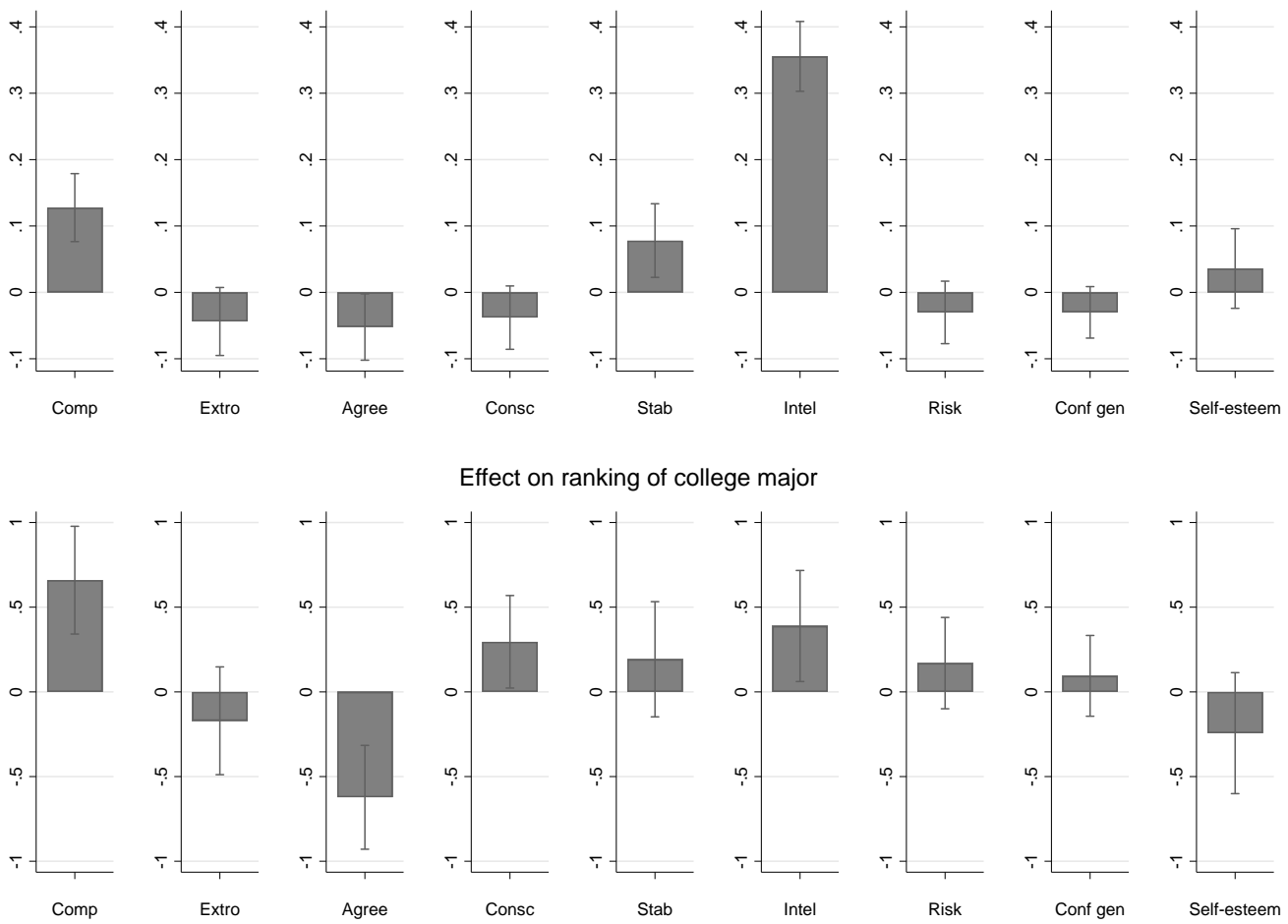

Note: Each figure shows the coefficient from a separate OLS regression of a dummy indicating that a respondent is in the top 30\% (vs bottom 30\%) on a given trait on an outcome variable. Each coefficient is from a separate regression controlling for gender, age, education level (in the case of the first two graphs), and all other traits (with the exception of confidence and self-esteem where we control for all other traits except the other confidence measure). The sample in each regression consists of respondents aged between 25 and 65 who are either in the bottom or top 30 percent on the given trait. Error bars represent 95-percent confidence intervals. 
to the top 30 percent on each trait not controlling for the other traits (that is, controlling only for age, gender and, in the case of income and occupational position, education).

We start with gross monthly income. Competitiveness is the strongest predictor followed by stability, confidence and self esteem. Agreeableness also significantly predicts income, albeit in a negative direction. The effects of the big five traits are in line with the literature. For example, Mueller and Plug (2006) equally find that stability predicts income positively whereas agreeableness is a negative predictor. Competitiveness is also one of the strongest predictors for holding a highlevel occupation, and the only one apart from intellectual openness that significantly predicts the outcome above all other traits.

The strongest predictor for holding a college degree is intellectual openness followed by competitiveness. It is useful to keep in mind that intellectual openness is closely related to cognitive skills (see, for example, Rammstedt, Danner, and Martin, 2016) for which we do not have a direct measure. Mueller and Plug (2006) find that controlling for scores in an IQ test substantially reduces the coefficient of openness in a regression of income on the big-five traits. The strong correlation between openness and college graduation is therefore likely partially due to openness capturing unobserved cognitive skills. Finally, competitiveness, agreeableness (negatively), openness and conscientiousness are the strongest predictors of having chosen a higher-ranked college major.

The question of which trait predicts best can also be answered in a complementary way by estimating the additional proportion of the variance in each outcome that is explained by each trait. In Figure 6, we show the increase in R-squared that is caused by adding each measure to regressions of our career outcomes on age, gender and all the other traits (plus, in the case of income and occupation, education level). In Figure A2 in the appendix, we show the increase in R-squared caused by each trait not controlling for the other traits.

The results in Figure 6 largely confirm those presented in Figure 5. Competitiveness is the strongest predictor of income and rank of college major and the second-strongest predictor (after intellectual openness) of holding a high-level occupation and having graduated from college.

Taken together, these estimation results confirm that competitiveness significantly predicts education and labor market outcomes conditional on a range of other traits which are commonly studied in the literature on non-cognitive skills (Borghans et al., 2008; Dohmen et al., 2011), indicating that competitiveness is a new trait that is not well-captured by existing measures of personality and economic preferences. The results in Figures A1 and A2 in the appendix, where we show the effects of each trait when not controlling for the other traits, confirm this picture. Competitiveness is consistently one of the strongest predictors, meaning that if one has to choose a single trait to predict the education and labor market outcomes of an individual, competitiveness is more often than not one of the top choices.

In the appendix, we also present results for our second unincentivized measure of competitiveness, the hypothetical choice in the Niederle-Vesterlund experiment. The results in Table B1 and 
Figure 6: Predictive power of individual traits compared (whole sample): effect on R-squared conditional on all other traits
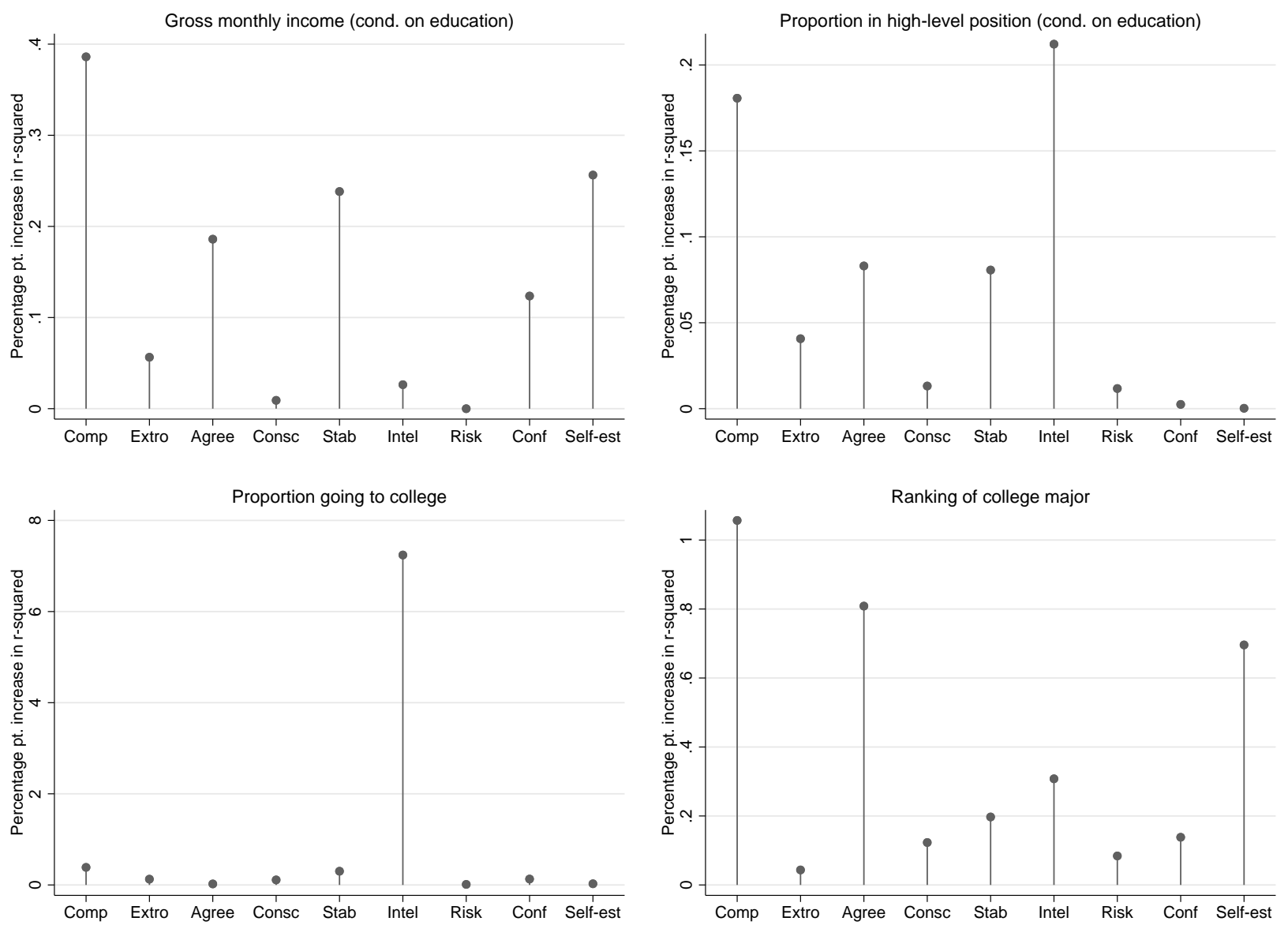

Note: the figures show the percentage point increase in R-squared in OLS regressions of a given trait variable on an outcome variable. Each effect is from a separate regression controlling for gender, age, education level (in the case of the first two graphs), and all other traits (with the exception of confidence and self-esteem where we control for all other traits except the other confidence measure). The sample consists of respondents aged between 25 and 65 . 
Figure B1 show that this binary measure predicts the same outcomes as our incentivized measure and our 11-point survey question. Conditional on gender and age, individuals who say they would compete in an incentivized experiment earn 265 Euros more per month (147 conditional on education), are 8 percentage points more likely to hold a high-level position (5 conditional on education), 8 percentage points more likely the hold a college degree, and, conditional on having gone to college, have picked a more lucrative major. However, these effects are consistently lower than those obtained with the incentivized choice measure and are less robust to controlling for other traits. When we add both of our unincentivized measures to our regressions, the coefficients on our 11-point measure hardly change while the coefficients on the hypothetical measure tend to become insignificant. We conclude that our 11-point questionnaire item is a better measure of competitiveness, on top of being quicker (and therefore cheaper) to elicit. ${ }^{25}$

However, in situations where it is not too costly to elicit both measures, the hypothetical measure still adds significant additional explanatory power. In Figure B2 in the appendix, we replicate the analysis in Figure 6 using both measures of competitiveness simultaneously. Using both measures leads to meaningful increases in the variance explained by competitiveness relative to using the 11-point measure alone.

\subsection{Competitiveness and risk attitudes}

Two recent papers argue that a large part of the gender difference in competitiveness, as measured by the Niederle and Vesterlund (2007) design, can be explained by gender differences in risk preferences and confidence (Gillen, Snowberg, and Yariv, 2019; van Veldhuizen, 2017). While these papers concentrate on the gender difference in competitiveness, their results raise the question whether competitiveness, rather than being a new, separate trait, is well captured by risk preferences and confidence in one's own relative performance. Our results indicate that competitiveness, risk and confidence are three separate traits which predict outcomes independently or even predict different outcomes. For example, Table 3 and Figure 5 show that our survey measure of competitiveness significantly predicts education and labor market variables even when controlling for survey measures of risk preferences, confidence, self-esteem and personality. Neither the effects of risk preferences nor of confidence are consistently robust to controlling for the other traits.

The four outcomes we consider - income, professional position, education level and major choice - are not necessarily directly linked to risk taking (for instance, being willing to compete against others is arguably more important for moving up the corporate hierarchy than being willing to take risk). Here, we want to go a step further in establishing that competitiveness and risk attitudes are separate traits that predict different outcomes by considering choices that are risky but not necessarily competitive. To obtain a non-arbitrary selection of such outcomes, we pick the four outcomes that were studied in the seminal study of Dohmen et al. (2011): the propensities to invest

\footnotetext{
${ }^{25}$ The hypothetical measure requires an explanation of the experimental design of Niederle and Vesterlund (2007).
} 
in stocks, practice sport, be self-employed, and smoke. Arguably only one of the four, practicing sports, is obviously related to enjoying competition (self-employed people have competitors but so do employees). ${ }^{26}$

We use the same method as in the previous section to estimate the predictive power of our trait measures for these risky outcomes. Figure 7 shows the difference in outcomes between individuals in the top 30\% and individuals in the bottom 30\% on each trait, controlling for age and gender. We replicate the Dohmen et al. (2011) result that risk seeking is a significant predictor of all four outcomes. As expected, competitiveness does not predict investing in stocks, being self-employed or smoking. On the other hand, competitiveness is the strongest predictor of practicing sports. This analysis further underlines that competitiveness and risk attitudes are both relevant individual traits which predict different economically important outcomes and should therefore be accounted for separately.

\subsection{Is there a dark side of competitiveness?}

So far, we find that competitiveness is strongly associated with better education and labor market outcomes. However, this does not mean that competitiveness is also associated with better wellbeing or social outcomes. For example, it may be that being competitive is detrimental for one's social life or intimate relationships. It may also be that competitive people are more selfish or less socially oriented. Looking at the correlations between competitiveness and other traits in Table A1, this seems a priori unlikely. Competitiveness is positively correlated with extroversion, conscientiousness, stability and intellectual openness, and is unrelated to agreeableness. Moreover, competitiveness is positively correlated with confidence and self-esteem. To further explore whether competitiveness has a dark side, in Table 4 we regress indicators of self-rated wellbeing and social preferences as well as objective wellbeing measures on our unincentivized measure of competitiveness using the same specifications as in Table 3.

In panels $\mathrm{A}$ and $\mathrm{B}$, we use self-rated measures of happiness and life satisfaction (on a scale from 0 to 10). People who rate themselves as more competitive are also happier and more satisfied with their lives, and this is true even when controlling for education level, other personality traits, confidence and self-esteem. In panel C, we use an objective measure of wellbeing, namely whether an individual is taking medicine to treat depression or anxiety. Individuals who rate themselves as one point more competitive are between 0.4 and 0.8 percentage points less likely to take such medication. This is a sizeable effect keeping in mind that 5.9 percent of individuals in the sample were taking medication for depression or anxiety at the time of either the 2017 or the 2016 core

\footnotetext{
${ }^{26}$ Some past studies have found correlations between willingness to compete and entrepreneurship. Bönte and Piegeler (2013) find a significant correlation using the Eurobarometer 283 survey on entrepreneurship which contains an unincentivized survey measure of competitiveness. Urbig et al. (2019), in a lab-in-the-field study conducted in a shopping mall, find that individuals who compete in an incentivized task are more likely to have ever been self-employed or to plan to become self-employed in the future.
} 
Figure 7: Predictive power of individual traits compared (whole sample): effect of moving from bottom 30 percent to top 30 percent
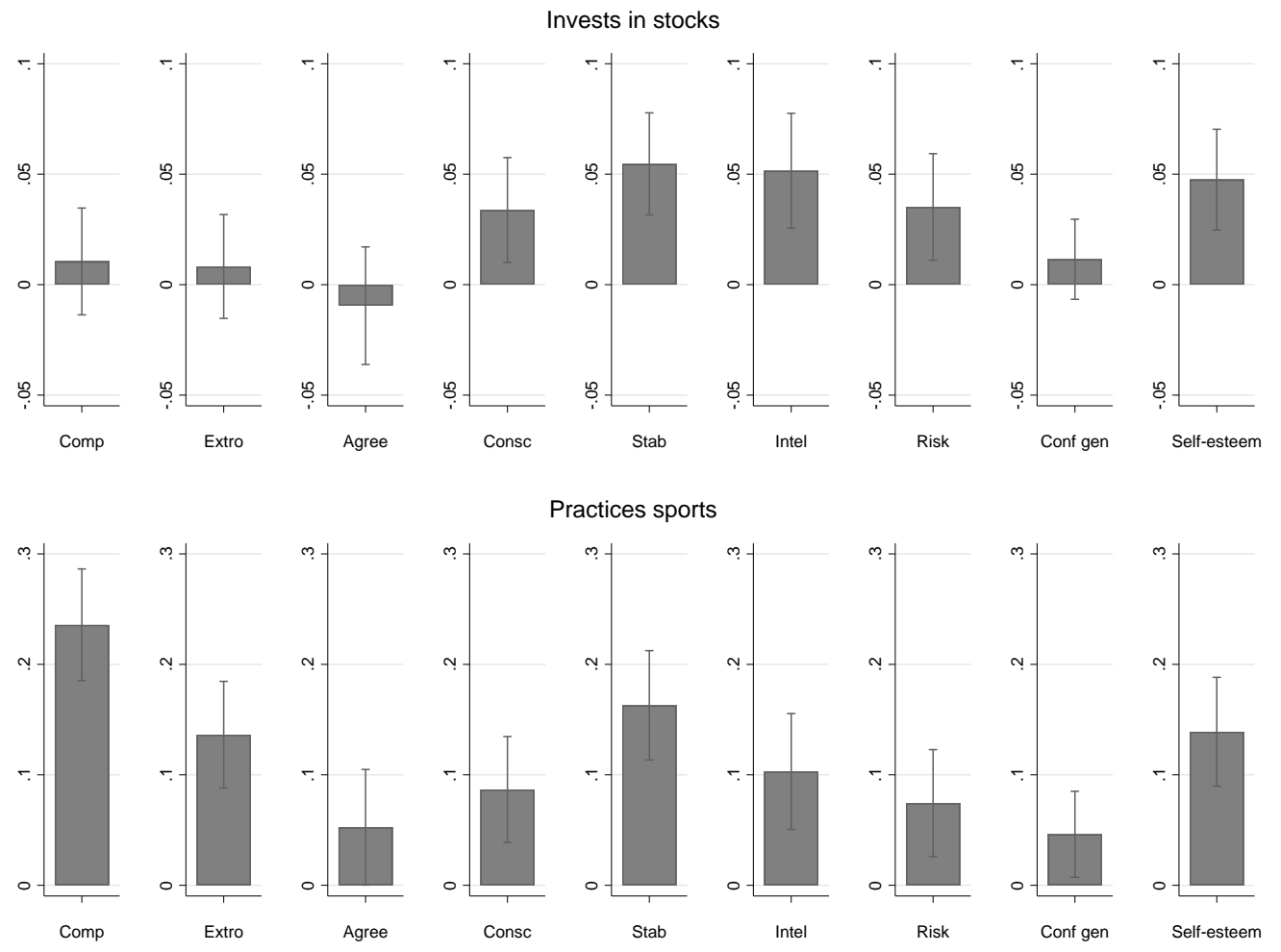

Practices sports
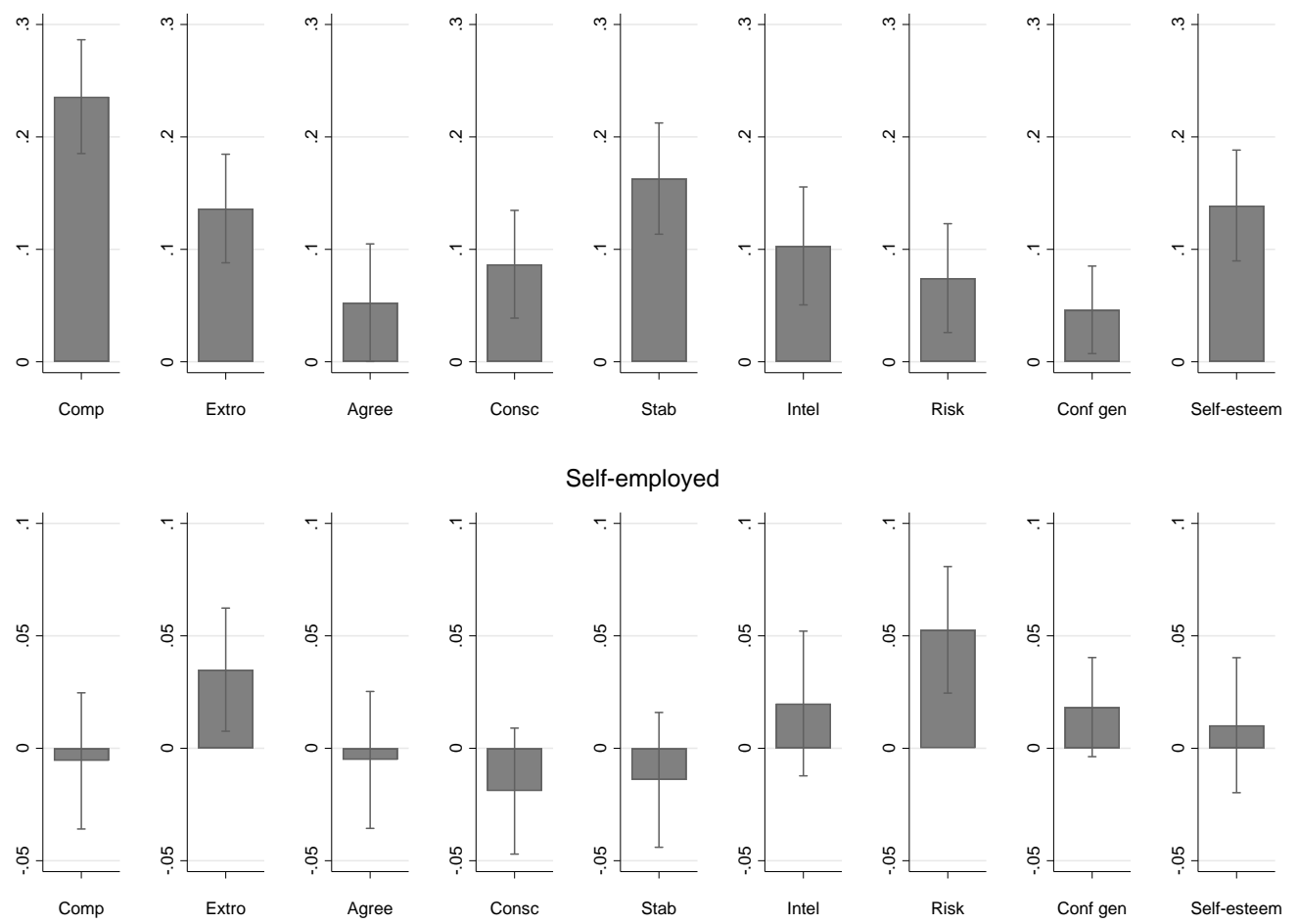

Self-employed
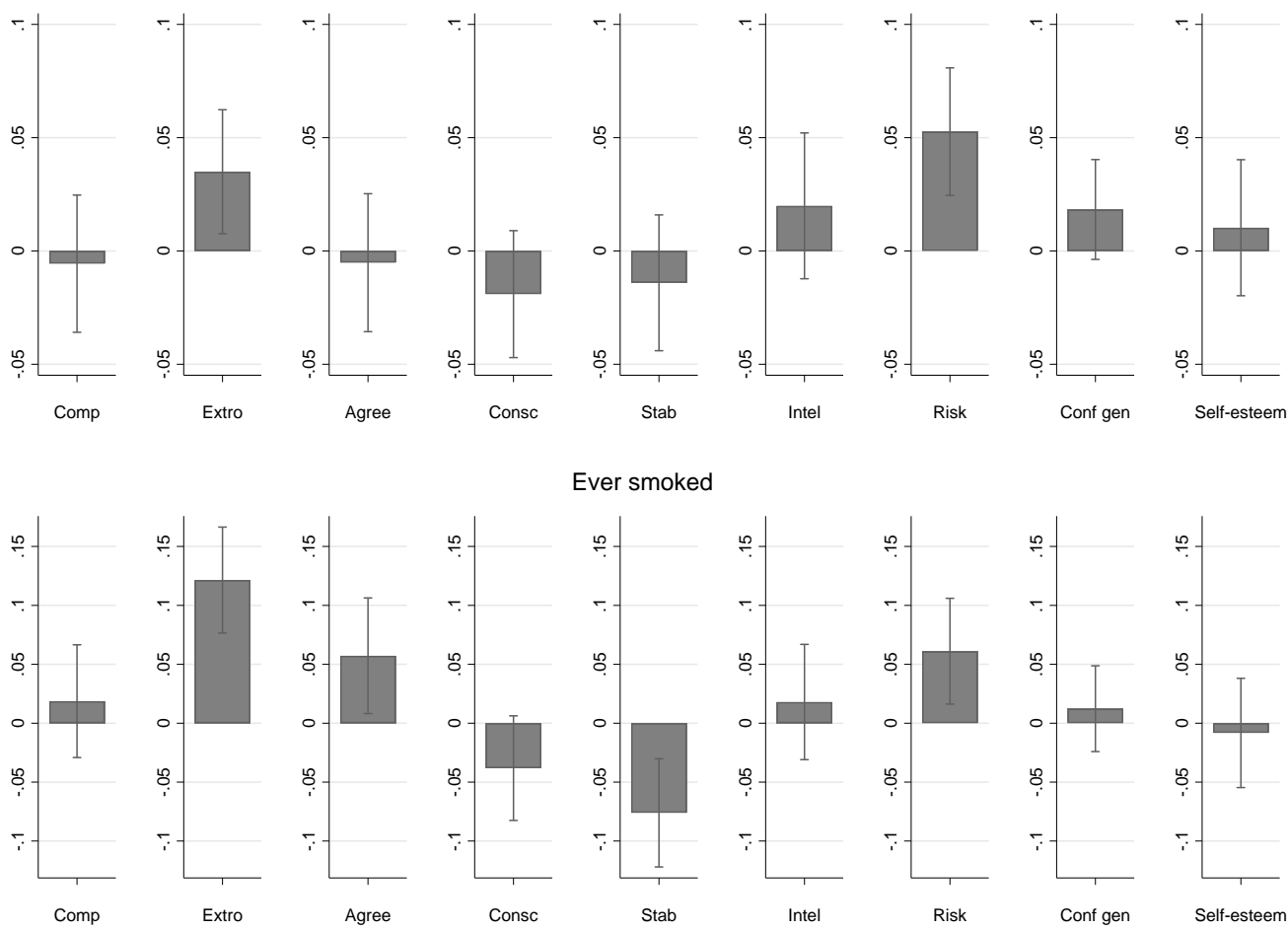

Ever smoked
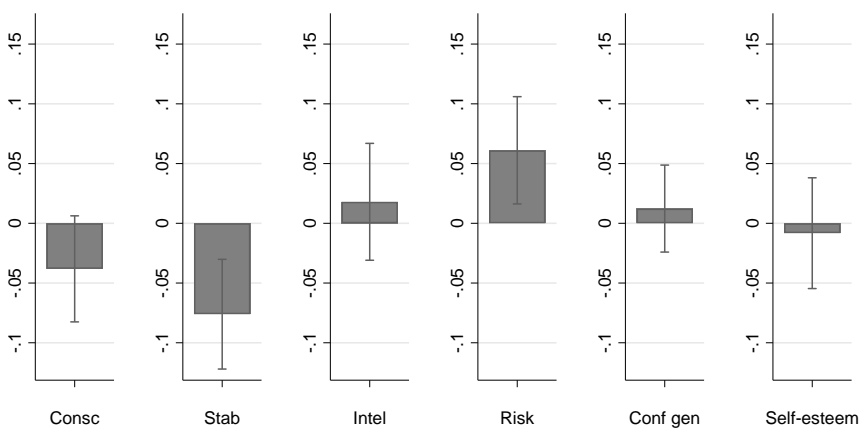

Note: the figures show coefficients from OLS regressions of a dummy indicating that a respondent is in the top $30 \%$ (vs bottom 30\%) on a given trait on an outcome variable. Each coefficient is from a separate regression controlling for gender, age, and age squared. The sample in each regression consists of respondents aged between 25 and 65 who are either in the bottom or top 30 percent on the given trait. Error bars represent 95-percent confidence intervals. 
health questionnaire.

We next look at how individuals connect to others. In panels D and E, we show that more competitive individuals are no less likely to have a partner or to be married. For a more general indicator of social connections, in Panel F we use the "Inclusion of Others in the Self" scale (Aron, Aron, and Smollan, 1992) which is included in the core personality questionnaire. Competitive people feel significantly closer to others, although this correlation is well-captured by other personality traits.

Finally, we ask whether competitive people differ from less competitive people in their social preferences. In Panels G-I, we use three measures from the core personality questionnaire. The first is a general measure of trust, asking respondents whether they think most people can be trusted on a scale from 0 to 10. The other two questions are included in a list of values where respondents judge how important these values are as a "guiding principle" in their lives on a scale from 1 to 7 . The two values we include are "helpful" and "loving". We find that individuals who are more competitive give more importance to being helpful and loving while there is no significant relationship between competitiveness and trust.

Overall, these results do not give any indication of a dark side of competitiveness. People who rate themselves as being more competitive, on top of being more successful are also happier, feel closer to others, are no less likely to be in a relationship and give more importance to being helpful and loving.

\subsection{Gender differences in competitiveness}

A large experimental literature documents gender differences in competitiveness (Gneezy, Niederle, and Rustichini, 2003; Niederle and Vesterlund, 2007; Niederle, 2016). Figure 8 shows that this is also true for the competitiveness measures used in this paper. While 34 percent of working-age men choose to compete in the experiment, only 22 percent of working-age women do so $(\mathrm{p}<0.001$; chi-squared test). ${ }^{27} 65$ percent of men and 47 percent of women rate their competitiveness as at or above the median $(\mathrm{p}<0.001){ }^{28}$ In the right-most panel, we show a histogram of competitiveness levels by gender which reveals large gender differences in the tails. 11 percent of men and 5 percent of women rate themselves as extremely competitive (9 or 10 on a $0-10$ scale). On the other hand, 9 percent of women and 5 percent of men rate their competitiveness as very low (0-2).

We also observe gender differences in most of the other traits we consider. Figure A3 in the appendix graphs the gender difference in each trait where trait measures have been standardized to have mean zero and a standard deviation of one. Apart from being less competitive, women are

\footnotetext{
${ }^{27}$ This difference is smaller than in some lab studies with university students but in line with the results of Boschini et al. (2019) who use a representative sample of the Swedish population and Buser, Peter, and Wolter (2018) who use a sample of secondary students that covers all ability levels.

${ }^{28}$ Due to the discrete nature of the competitiveness measure, slightly more than 50 percent of individuals are at or above the median of 7 ( 54 percent).
} 
Table 4: Wellbeing and competitiveness

\begin{tabular}{|c|c|c|c|c|c|c|c|}
\hline & $(1)$ & $(2)$ & $(3)$ & $(4)$ & $(5)$ & $(6)$ & $(7)$ \\
\hline \multicolumn{8}{|c|}{ A. Self-rated happiness (OLS) } \\
\hline Competitiveness & $\begin{array}{c}0.080^{* * *} \\
(0.014)\end{array}$ & $\begin{array}{c}0.086^{* * *} \\
(0.014)\end{array}$ & $\begin{array}{c}0.040^{* * *} \\
(0.013)\end{array}$ & $\begin{array}{c}0.040^{* * *} \\
(0.014)\end{array}$ & $\begin{array}{c}0.080^{* * *} \\
(0.014)\end{array}$ & $\begin{array}{c}0.038^{* * *} \\
(0.013)\end{array}$ & $\begin{array}{c}0.038^{* * *} \\
(0.014)\end{array}$ \\
\hline $\mathrm{N}$ & 3030 & 3030 & 3030 & 3030 & 3028 & 3028 & 3028 \\
\hline adj. R-sq & 0.016 & 0.016 & 0.206 & 0.256 & 0.023 & 0.207 & 0.256 \\
\hline \multicolumn{8}{|c|}{ B. Self-rated life satisfaction (OLS) } \\
\hline Competitiveness & $\begin{array}{c}0.082^{* * *} \\
(0.015)\end{array}$ & $\begin{array}{c}0.091^{* * * *} \\
(0.015)\end{array}$ & $\begin{array}{c}0.043^{* * *} \\
(0.014)\end{array}$ & $\begin{array}{c}0.040^{* * *} \\
(0.014)\end{array}$ & $\begin{array}{c}0.084^{* * *} \\
(0.015)\end{array}$ & $\begin{array}{c}0.040^{* * *} \\
(0.014)\end{array}$ & $\begin{array}{c}0.037^{* * *} * \\
(0.014)\end{array}$ \\
\hline $\mathrm{N}$ & 3045 & 3045 & 3045 & 3045 & 3043 & 3043 & 3043 \\
\hline adj. R-sq & 0.013 & 0.017 & 0.203 & 0.263 & 0.026 & 0.205 & 0.265 \\
\hline \multicolumn{8}{|c|}{ C. Taking medicine for depression or anxiety (OLS) } \\
\hline Competitiveness & $\begin{array}{c}-0.009 * * * \\
(0.002)\end{array}$ & $\begin{array}{c}-0.008 * * * \\
(0.002)\end{array}$ & $\begin{array}{c}-0.004^{*} \\
(0.002)\end{array}$ & $\begin{array}{c}-0.006^{* *} \\
(0.003)\end{array}$ & $\begin{array}{c}-0.007^{* * *} \\
(0.002)\end{array}$ & $\begin{array}{c}-0.004^{*} \\
(0.002)\end{array}$ & $\begin{array}{c}-0.006^{* *} \\
(0.003)\end{array}$ \\
\hline $\mathrm{N}$ & 2951 & 2951 & 2951 & 2951 & 2948 & 2948 & 2948 \\
\hline adj. R-sq & 0.006 & 0.009 & 0.088 & 0.092 & 0.014 & 0.089 & 0.094 \\
\hline \multicolumn{8}{|c|}{ D. Has a partner (OLS) } \\
\hline Competitiveness & $\begin{array}{l}0.007^{*} \\
(0.004)\end{array}$ & $\begin{array}{c}0.007^{* *} \\
(0.004)\end{array}$ & $\begin{array}{c}0.003 \\
(0.004)\end{array}$ & $\begin{array}{c}0.005 \\
(0.004)\end{array}$ & $\begin{array}{c}0.006 \\
(0.004)\end{array}$ & $\begin{array}{c}0.002 \\
(0.004)\end{array}$ & $\begin{array}{c}0.004 \\
(0.004)\end{array}$ \\
\hline $\mathrm{N}$ & 2997 & 2997 & 2997 & 2997 & 2994 & 2994 & 2994 \\
\hline adj. R-sq & 0.001 & 0.005 & 0.012 & 0.020 & 0.011 & 0.020 & 0.026 \\
\hline \multicolumn{8}{|c|}{ E. Is married (OLS) } \\
\hline Competitiveness & $\begin{array}{c}-0.007 \\
(0.004)\end{array}$ & $\begin{array}{c}0.006 \\
(0.004)\end{array}$ & $\begin{array}{c}0.004 \\
(0.005)\end{array}$ & $\begin{array}{l}0.009^{*} \\
(0.005)\end{array}$ & $\begin{array}{c}0.006 \\
(0.004)\end{array}$ & $\begin{array}{c}0.003 \\
(0.005)\end{array}$ & $\begin{array}{l}0.008^{*} \\
(0.005)\end{array}$ \\
\hline$\overline{\mathrm{N}}$ & 3082 & 3082 & 3082 & 3082 & 3079 & 3079 & 3079 \\
\hline adj. R-sq & 0.000 & 0.102 & 0.110 & 0.113 & 0.102 & 0.111 & 0.114 \\
\hline \multicolumn{8}{|c|}{ F. Feels close to other people (inclusion of the other in the self scale) (OLS) } \\
\hline Competitiveness & $\begin{array}{l}0.029^{*} \\
(0.015)\end{array}$ & $\begin{array}{c}0.071^{* * *} \\
(0.015)\end{array}$ & $\begin{array}{c}0.028^{* *} \\
(0.014)\end{array}$ & $\begin{array}{c}0.023 \\
(0.015)\end{array}$ & $\begin{array}{c}0.069^{* * *} \\
(0.015)\end{array}$ & $\begin{array}{c}0.027^{*} \\
(0.014)\end{array}$ & $\begin{array}{c}0.022 \\
(0.015)\end{array}$ \\
\hline $\mathrm{N}$ & 3079 & 3079 & 3079 & 3079 & 3076 & 3076 & 3076 \\
\hline adj. R-sq & 0.001 & 0.051 & 0.252 & 0.252 & 0.053 & 0.252 & 0.252 \\
\hline \multicolumn{8}{|l|}{ G. Trust (OLS) } \\
\hline Competitiveness & $\begin{array}{c}0.028 \\
(0.022)\end{array}$ & $\begin{array}{c}0.024 \\
(0.023)\end{array}$ & $\begin{array}{l}-0.022 \\
(0.022)\end{array}$ & $\begin{array}{l}-0.018 \\
(0.023)\end{array}$ & $\begin{array}{c}-0.001 \\
(0.022)\end{array}$ & $\begin{array}{c}-0.036^{*} \\
(0.022)\end{array}$ & $\begin{array}{c}-0.035 \\
(0.023)\end{array}$ \\
\hline $\mathrm{N}$ & 3065 & 3065 & 3065 & 3065 & 3063 & 3063 & 3063 \\
\hline adj. R-sq & 0.000 & 0.000 & 0.100 & 0.103 & 0.080 & 0.154 & 0.157 \\
\hline \multicolumn{8}{|c|}{ H. Values: helpful (OLS) } \\
\hline Competitiveness & $\begin{array}{c}0.015 \\
(0.010) \\
\end{array}$ & $\begin{array}{c}0.035^{* * *} * \\
(0.010)\end{array}$ & $\begin{array}{c}0.024^{* * *} \\
(0.009)\end{array}$ & $\begin{array}{c}0.022^{* *} \\
(0.010)\end{array}$ & $\begin{array}{c}0.038^{* * *} \\
(0.010)\end{array}$ & $\begin{array}{c}0.027^{* * * *} \\
(0.009)\end{array}$ & $\begin{array}{c}0.026^{* * *} \\
(0.010)\end{array}$ \\
\hline $\mathrm{N}$ & 3079 & 3079 & 3079 & 3079 & 3076 & 3076 & 3076 \\
\hline adj. R-sq & 0.001 & 0.029 & 0.168 & 0.183 & 0.036 & 0.180 & 0.194 \\
\hline \multicolumn{8}{|c|}{ I. Values: loving (OLS) } \\
\hline Competitiveness & $\begin{array}{c}0.016 \\
(0.010)\end{array}$ & $\begin{array}{c}0.040^{* * *} \\
(0.010)\end{array}$ & $\begin{array}{c}0.024^{* *} \\
(0.010)\end{array}$ & $\begin{array}{c}0.021^{* *} \\
(0.010)\end{array}$ & $\begin{array}{c}0.042^{* * *} \\
(0.010)\end{array}$ & $\begin{array}{c}0.027^{* * *} * \\
(0.010)\end{array}$ & $\begin{array}{c}0.024^{* *} \\
(0.010)\end{array}$ \\
\hline $\mathrm{N}$ & 3079 & 3079 & 3079 & 3079 & 3076 & 3076 & 3076 \\
\hline adj. R-sq & 0.001 & 0.049 & 0.176 & 0.192 & 0.054 & 0.186 & 0.201 \\
\hline Gender, age & & $\sqrt{ }$ & $\sqrt{ }$ & $\sqrt{ }$ & $\sqrt{ }$ & $\sqrt{ }$ & $\sqrt{ }$ \\
\hline Education level & & & & & $\sqrt{ }$ & $\sqrt{ }$ & $\sqrt{ }$ \\
\hline Big 5 & & & $\sqrt{ }$ & $\sqrt{ }$ & & $\sqrt{ }$ & $\sqrt{ }$ \\
\hline Confidence and risk & & & & $\sqrt{ }$ & & & $\sqrt{ }$ \\
\hline
\end{tabular}

Note: Each estimate comes from a separate regression of the outcome indicated in the panel title on the unincentivized competitiveness variable and the control variables indicated in the bottom rows. Education level is measured by dummy variables indicating different levels. Big 5 are obtained from the 50 question elicitation of the big 5 personality traits: extroversion, agreeableness, conscientiousness, stability and intellectual openness. Risk attitudes is measured by the Dohmen et al. (2011) survey measure which we elicited at the same time as our unincentivized measures of competitiveness. We use two measures for confidence: the Rosenberg's self-esteem scale and their confidence in their own capabilities judged on a seven-point scale. Standard errors in parentheses. */**/*** indicates significance at the $10 / 5 / 1 \%$-level. 
Figure 8: Gender differences in competitiveness by measure
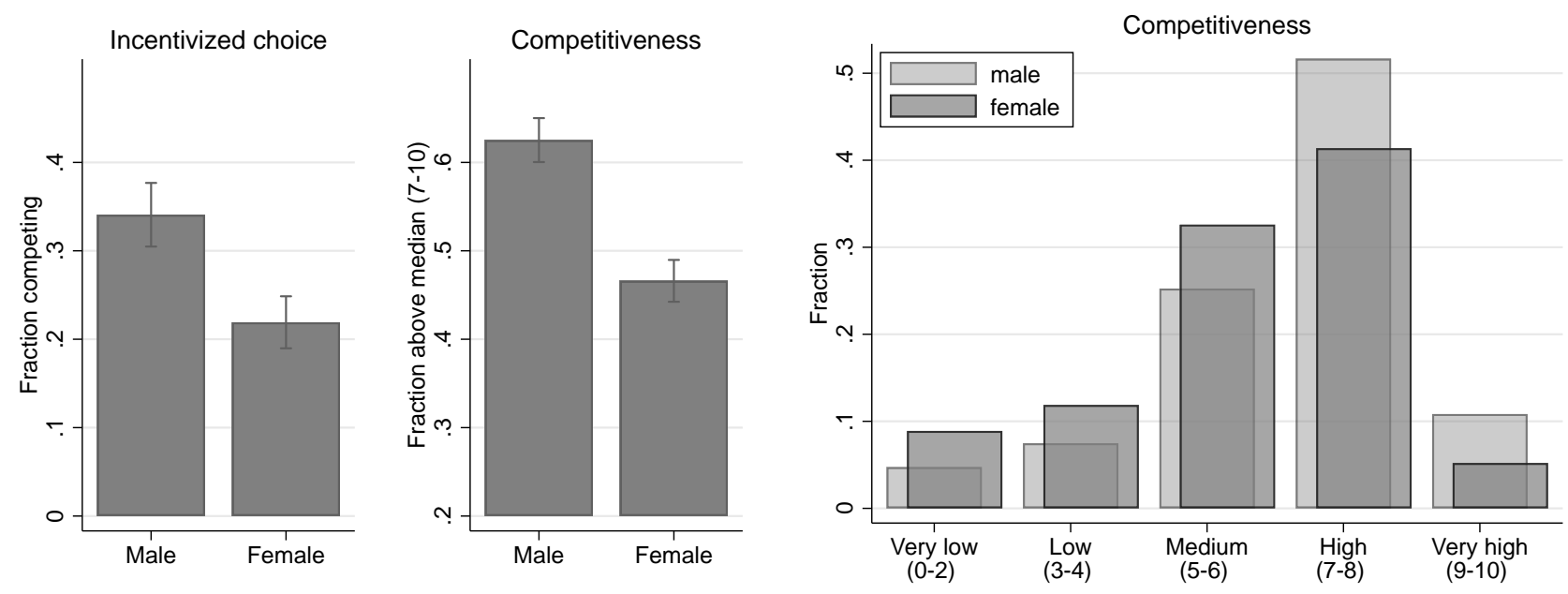

Note: The left panel shows the fractions of men and women competing in the incentivized choice experiment. The middle panel shows the means for men and women on the unincentivized general competitiveness question. The right panel shows the distributions for men and women on the unincentivized general competitiveness question. The sample consists of respondents aged between 25 and 65 . Error bars represent 95-percent confidence intervals.

more agreeable and more conscientious while men rate themselves higher on stability, intellectual openness, risk seeking and both confidence measures. There is no gender difference in extroversion. These differences are in line with findings in the literature on gender differences in risk seeking (Croson and Gneezy, 2009) and confidence (Niederle, 2016). The gender differences in agreeableness, conscientiousness and mental stability also go in the expected direction, whereas many other studies find no difference in openness (Mueller and Plug, 2006; Schmitt et al., 2008).

Three of the four education and labor market variables exhibit significant gender differences. Conditional on age and education level, working age women in our sample earn 1414 Euros less per month $(\mathrm{p}<0.001 ;$ OLS) and are 11 percentage points less likely to hold a high-level occupation $(\mathrm{p}<0.001)$. Their likelihood of going to college is similar to that of men, but conditional on going to college, they pick a major that is ranked 1.3 positions lower in the ranking by income prospects $(\mathrm{p}<0.001)$.

In Figure 9, we ask whether our unincentivized measure of competitiveness, as well as the other trait measures, can explain a significant part of these gender gaps. To do so, we estimate the percentage reduction in the gender gap upon controlling for each of the traits separately and jointly. ${ }^{29}$

Controlling for the unincentivized competitiveness measure reduces the gender gap in income conditional on education level by 4.3 percent. Competitiveness is among the traits which explain most of the gender gap in income, together with stability (5.3 percent) and general confidence (3.6

\footnotetext{
${ }^{29}$ These coefficients are from OLS regressions of the education and labor market variables on a gender dummy, a second-degree polynomial in age, and (in the case of income and occupation) education level dummies for the sample of 25 to 65 -year olds who answered our questionnaire.
} 
Figure 9: Percentage reduction in gender differences when adding each individual trait separately and jointly (whole sample)

Effect on gender difference in gross monthly income (cond. on education level)

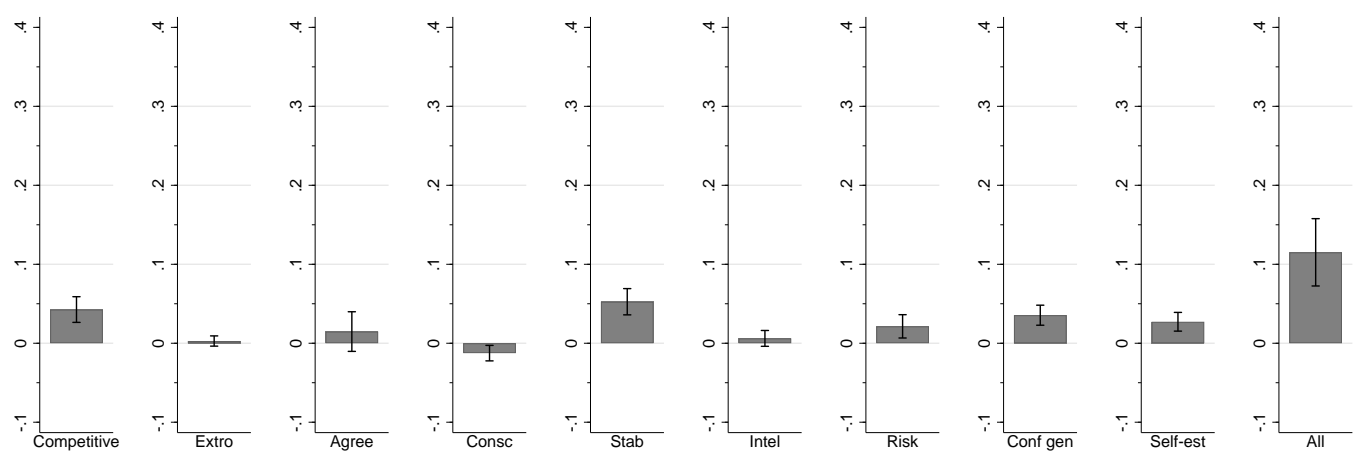

Effect on gender difference in gross monthly income (college-educated only)

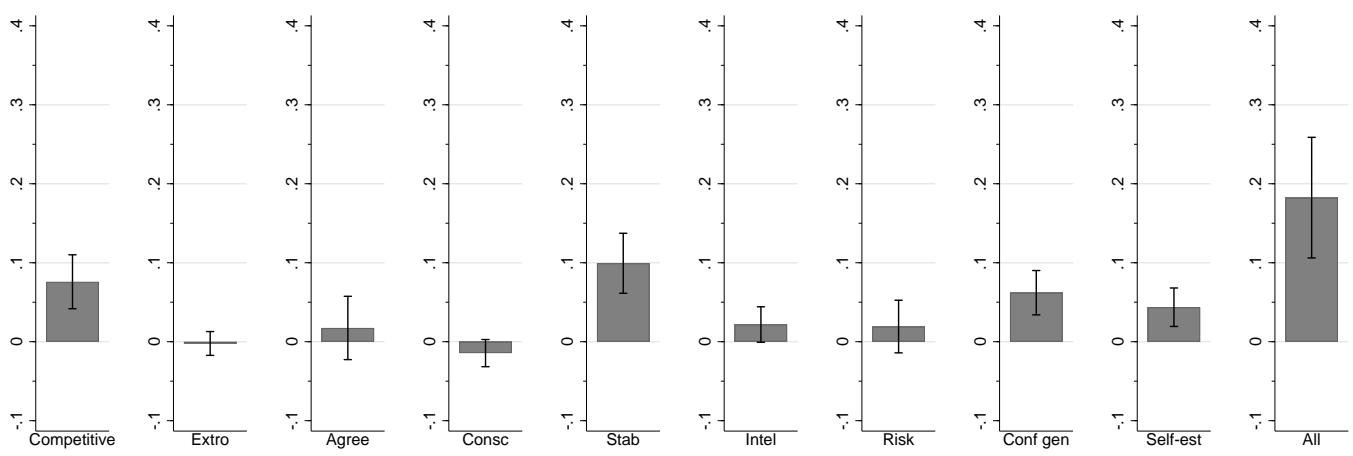

Effect on gender difference in proportion in high-level professional or managerial position (cond. on education level)
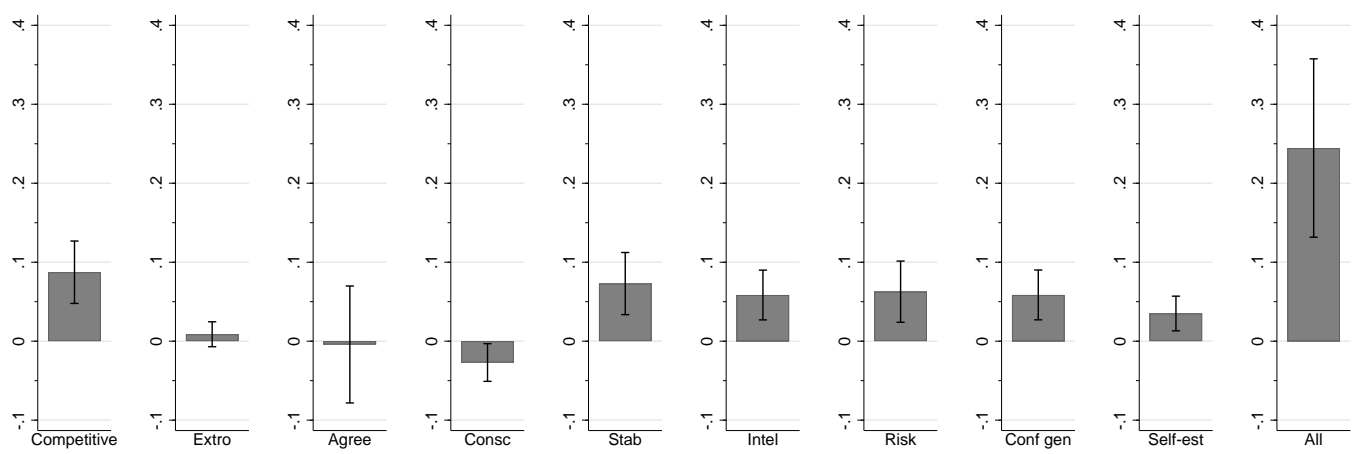

Effect on gender difference in ranking of college major
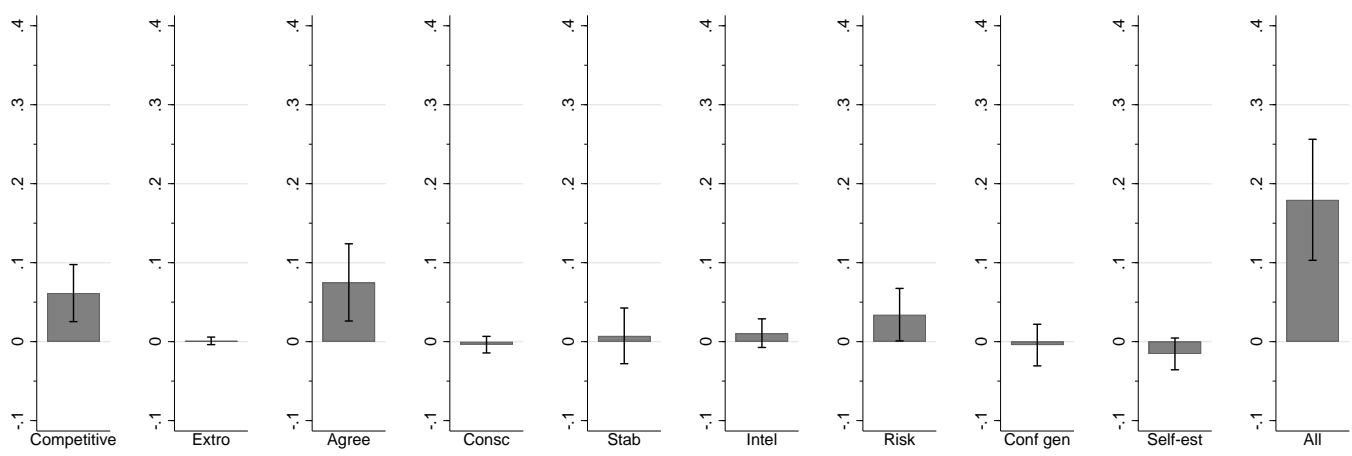

Note: The figures show the part (in percent) of the gender gap in an outcome variable that can be explained by each trait separately and jointly. The estimates are from separate OLS regressions of gender, age, and age squared on an outcome variable with and without a trait variable added to the regression. The sample consists of respondents aged between 25 and 65 . Error bars represent 95-percent confidence intervals. 
percent). In the right-most graph in each panel, we estimate the proportion of the gender gap that is explained by all traits together. We estimate that around 12 percent of the gender gap in income in our sample can statistically be explained by the psychological traits we consider. Following previous results that the potential of competitiveness for explaining differences in educational career choices is highest at the top of the ability distribution (Buser, Peter, and Wolter, 2018), we repeat this exercise for college-educated individuals. Here, competitiveness explains 7.6 percent of the gender gap, while stability explains 9.9 percent and confidence 6.2 percent. All traits jointly explain roughly 18 percent of the gender difference in income for college-educated individuals.

Competitiveness also has the most explanatory power for the gender gap in holding a highlevel occupation conditional on education level (8.7 percent) followed by stability (7.3 percent), risk seeking (6.3 percent), confidence (5.9 percent), and intellectual openness (5.8 percent). All psychological traits jointly explain around 25 percent of the gender gap. For those who graduated from college, competitiveness (6.1 percent), agreeableness (7.5 percent) and risk seeking (3.4 percent) are the only significant explanatory factors for the gender gap in major choice. All traits jointly explain 18 percent of the gender gap.

In Figure B3 in the appendix, we repeat this exercise using both of our unincentivized competitiveness measures separately and jointly. While our 11-point survey question consistently does a better job explaining the gender gap, adding both measures jointly still leads to an increase in the part of the gender gap in outcomes that can be explained by competitiveness. The two measures can jointly explain 4.9 percent of the gender difference in income conditional on education, 9.6 percent of the gender difference in income for college graduates, 9.9 percent of the gender gap in holding a high-level position conditional on education, and 8.4 percent of the gender difference in major choice for college graduates.

On top of the widely observed gender difference, a small number of studies have also investigated age effects in competitiveness. Flory et al. (2018), in a sample of over 700 participants from villages in Malawi and a smaller US sample, find that the gender gap in competitiveness disappears above age 50 due to a large increase in the competitiveness of women. Mayr et al. (2012), in a sample of over 500 adults recruited in a US shopping mall, find a midlife-peak in competitiveness with men and women from 45 to 54 years old being more competitive than both their younger and their older counterparts. They find a significant gender difference for all ages. Bönte (2015), using an unincentivized survey measure of competitiveness, finds that the gender difference in competitiveness stays roughly constant across the life cycle.

We will now check whether we detect similar patterns for our measures of competitiveness in our representative sample. Figure 10 shows the fraction of men and women competing in the experiment as well as the average competitiveness score for five ten-year groups spanning the ages of 15 to 64 . Both measures show a general decline with age. We observe neither an increase in the competitiveness for women above 50 nor a midlife peak. 
Figure 10: Competitiveness by gender and age
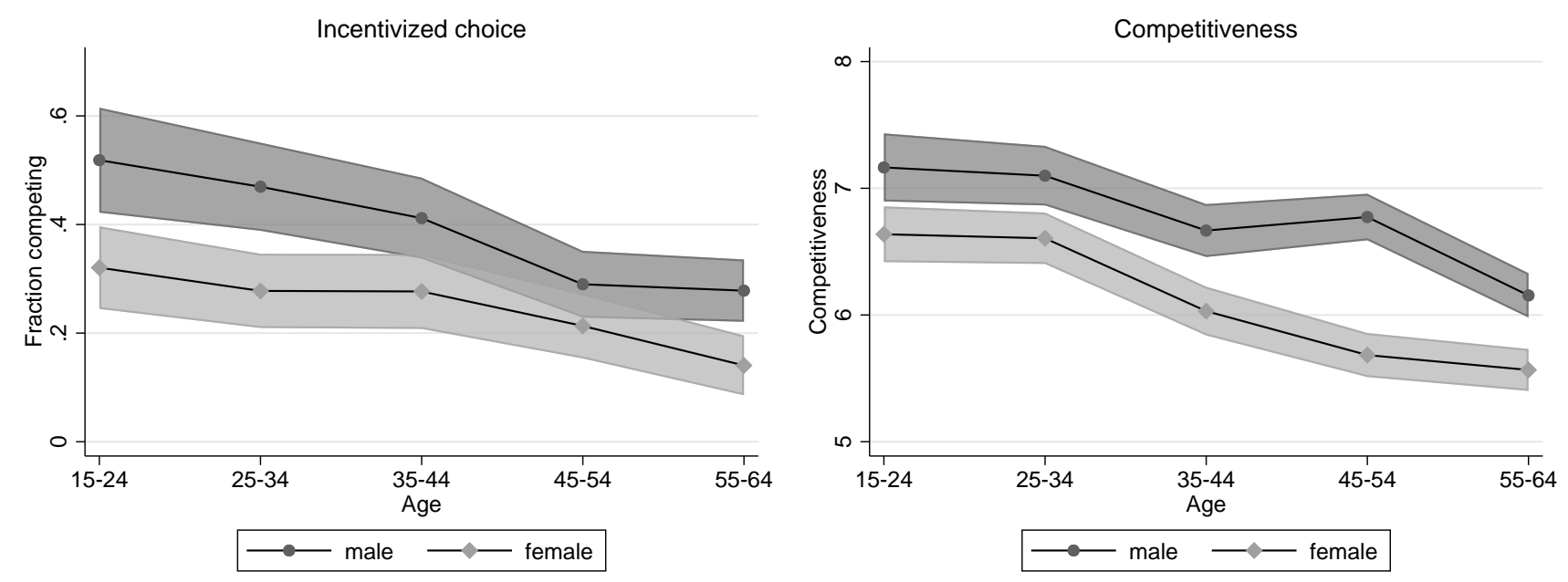

Note: The figures show the fraction competing and the mean competitiveness score (plus their $95 \%$ confidence intervals) per 10-years age groups by gender.

\section{Conclusion}

A large literature documents individual and gender differences in competitiveness in the lab. Following up on this literature, a number of studies link competitiveness, typically measured through an incentivized choice experiment in a classroom setting, to educational decisions and early career choices. Many important questions remain unanswered, including whether competitiveness predicts choices and outcomes along the whole career cycle, where individual and gender differences in competitiveness originate and how average competitiveness differs across other demographic groups and across countries. Answering these questions requires new ways of measuring preferences for competition that do not necessitate gathering respondents in the same physical location. Many applications will require a measure that can be added to large-scale surveys without any significant increase in survey time (and therefore cost).

In this paper we introduce such measures of competitiveness. The first is incentivized and is an online adaptation of the original Niederle-Vesterlund measure. The second is a single unincentivized survey question which can be quickly elicited in any setting. The two measures are strongly correlated at the individual level and both measures are strong and consistent predictors of completed level of education, field of study in college, occupation and income. The predictive power of the unincentivized measure for these outcomes is robust to controlling for other traits, including risk seeking, confidence and the big five personality traits. For most outcomes, the predictive power of competitiveness exceeds that of the other traits.

The new survey measure will open up new avenues for research that we aim to explore in future work. This includes repeat elicitation of competitiveness in survey panels, which allows following 
people over time and using panel data methods to better isolate causal pathways. Some European survey panels allow linking to registry data, which opens up the possibility to make use of natural experiments to explore the causal origins of individual differences in competitiveness. Furthermore, our survey question can be used for eliciting competitiveness in cross-country surveys.

We also contribute to the literature on gender differences in the labor market. We find that gender differences in competitiveness can explain 5-10\% of the observed gender differences in education and labor market outcomes and that gender differences in competitiveness, risk seeking, confidence and the big five personality traits combined can explain up to $25 \%$ of gender differences. Our results are also relevant to the ongoing discussion in the experimental economics literature on whether gender differences in willingness to compete in the lab are due to individual differences in preferences for competition or rather due to differences in beliefs and risk preferences. We show that competitiveness and risk attitudes predict a separate set of outcomes. Risk attitudes are only weakly related to career outcomes. On the other hand, risk attitudes, but not competitiveness, predict choices that are intrinsically risky but not competitive (investing in stock, self-employment and smoking).

The relations that we have unveiled are (conditional) associations and cannot be interpreted causally. Neither omitted variable bias nor reversed causality can be ruled out. The introduction and validation of a unincentivized survey measure of competitiveness, however, makes it possible to measure competitiveness repeatedly and in much larger samples than has been the case so far. This in turn paves the way for research that can uncover which factors influence competitiveness, and, in cases where these factors can be manipulated or considered exogenous, isolate the causal impact of competitiveness on outcomes. Such research could also shed light on the question to what extent competitiveness is a productive trait and to what extent it is merely a trait that helps people to enter certain occupations without actually being more productive. 


\section{References}

Almås, Ingvild, Alexander W Cappelen, Kjell G Salvanes, Erik Ø Sørensen, and Bertil Tungodden. 2016. "What explains the gender gap in college track dropout? Experimental and administrative evidence." American Economic Review 106 (5):296-302.

Almlund, Mathilde, Angela Lee Duckworth, James Heckman, and Tim Kautz. 2011. "Personality psychology and economics." In Handbook of the Economics of Education, vol. 4. Elsevier, 1-181.

Aron, Arthur, Elaine N Aron, and Danny Smollan. 1992. "Inclusion of other in the self scale and the structure of interpersonal closeness." Journal of Personality and Social Psychology 63 (4):596.

Berge, Lars Ivar Oppedal, Kjetil Bjorvatn, Armando Jose Garcia Pires, and Bertil Tungodden. 2015. "Competitive in the lab, successful in the field?" Journal of Economic Behavior \&6 Organization 118:303-317.

Bertrand, Marianne. 2011. "New Perspectives on Gender." In Handbook of Labor Economics, vol. 4B, edited by Orley Ashenfelter and David Card. Elsevier, 1543 - 1590.

Bönte, Werner. 2015. "Gender differences in competitive preferences: new cross-country empirical evidence." Applied Economics Letters 22 (1):71-75.

Bönte, Werner, Sandro Lombardo, and Diemo Urbig. 2017. "Economics meets psychology: experimental and self-reported measures of individual competitiveness." Personality and Individual Differences 116:179-185.

Bönte, Werner and Monika Piegeler. 2013. "Gender gap in latent and nascent entrepreneurship: driven by competitiveness." Small Business Economics 41:961-987.

Borghans, Lex, Angela Lee Duckworth, James J. Heckman, and Bas ter Weel. 2008. "The Economics and Psychology of Personality Traits." Journal of Human Resources 43 (4):972-1059.

Boschini, Anne, Anna Dreber, Emma von Essen, Astri Muren, and Eva Ranehill. 2019. "Gender, risk preferences and willingness to compete in a random sample of the Swedish population." Journal of Behavioral and Experimental Economics 83:101467.

Buser, Thomas, Muriel Niederle, and Hessel Oosterbeek. 2014. "Gender, competitiveness and career choices." Quarterly Journal of Economics 129 (3):1409-1447.

Buser, Thomas, Noemi Peter, and Stefan Wolter. 2017. "Gender, Competitiveness, and Study Choices in High School: Evidence from Switzerland." American Economic Review 107 (5):125130 . 
—. 2018. "Gender, willingness to compete and career choices along the whole ability distribution." Working paper.

Buser, Thomas, Erik Plug, and Lydia Geijtenbeek. 2018. "Sexual orientation, competitiveness and income." Journal of Economic Behavior \& Organization 151:191-198.

Cortes, Patricia and Jessica Pan. 2018. "Occupation and Gender." In The Oxford Handbook of Women and the Economy. Oxford University Press.

Croson, Rachel and Uri Gneezy. 2009. "Gender differences in preferences." Journal of Economic Literature 47 (2):448-474.

Dohmen, Thomas, Armin Falk, David Huffman, Uwe Sunde, Jurgen Schupp, and Gert G. Wagner. 2011. "Individual risk attitudes: Measurement, determinants, and behavioral consequences." Journal of the European Economic Association 9 (3):522-550.

Falk, Armin, Anke Becker, Thomas Dohmen, David Huffman, and Uwe Sunde. 2016. "The preference survey module: A validated instrument for measuring risk, time, and social preferences." Working paper.

Falk, Armin and Florian Zimmermann. 2013. "A taste for consistency and survey response behavior." CESifo Economic Studies 59 (1):181-193.

Fallucchi, Francesco, Daniele Nosenzo, and Reuben Ernesto. 2020. "Measuring preferences for competition with experimentally-validated survey questions." Journal of Economic Behavior and Organzation forthcoming.

Flory, Jeffrey A, Uri Gneezy, Kenneth L Leonard, and John A List. 2018. "Gender, age, and competition: A disappearing gap?" Journal of Economic Behavior E Organization 150:256276.

Flory, Jeffrey A., Andreas Leibbrandt, and John A. List. 2015. "Do competitive workplaces deter female workers? A large-scale natural field experiment on job-entry decisions." Review of Economic Studies 82 (1):122-155.

Gillen, Ben, Erik Snowberg, and Leeat Yariv. 2019. "Experimenting with measurement error: Techniques with applications to the caltech cohort study." Journal of Political Economy 127 (4):18261863.

Gneezy, Uri, Muriel Niederle, and Aldo Rustichini. 2003. "Performance In Competitive Environments: Gender Differences." The Quarterly Journal of Economics 118 (3):1049-1074. 
Goldberg, L. R., J. A. Johnson, H. W. Eber, R. Hogan, M. C. Ashton, C. R. Cloninger, and H. G. Gough. 2006. "The international personality item pool and the future of public-domain personality measures." Journal of Research in Personality 40 (1):84-96.

Griffin-Pierson, Sharon. 1990. "The Competitiveness Questionnaire: A Measure of Two Components of Competitiveness." Measurement and evaluation in counseling and development $23(3): 108-15$.

Heckman, James J and Yona Rubinstein. 2001. "The importance of noncognitive skills: Lessons from the GED testing program." American Economic Review 91 (2):145-149.

Heckman, James J, Jora Stixrud, and Sergio Urzua. 2006. "The effects of cognitive and noncognitive abilities on labor market outcomes and social behavior." Journal of Labor Economics 24 (3):411482.

Houston, John, Paul Harris, Sandra McIntire, and Dientje Francis. 2002. "Revising the competitiveness index using factor analysis." Psychological Reports 90 (1):31-34.

Houston, John M, Paul B Harris, Kristina Howansky, and Sara M Houston. 2015. "Winning at work: Trait competitiveness, personality types, and occupational interests." Personality and Individual Differences 76:49-51.

Mayr, Ulrich, Dave Wozniak, Casey Davidson, David Kuhns, and William T Harbaugh. 2012. "Competitiveness across the life span: the feisty fifties." Psychology and aging 27 (2):278.

Mueller, Gerrit and Erik Plug. 2006. "Estimating the effect of personality on male and female earnings." ILR Review 60 (1):3-22.

Newby, Jennifer L and Rupert G Klein. 2014. "Competitiveness reconceptualized: Psychometric development of the competitiveness orientation measure as a unified measure of trait competitiveness." The Psychological Record 64 (4):879-895.

Niederle, Muriel. 2016. "Gender." In Handbook of Experimental Economics, edited by John Kagel and Alvin E. Roth. Princeton University Press, 353-375.

Niederle, Muriel and Lise Vesterlund. 2007. "Do women shy away from competition? Do men compete too much?" The Quarterly Journal of Economics 122 (3):1067-1101.

—. 2011. "Gender and competition." Annual Review of Economics 3 (1):601-630.

Rammstedt, Beatrice, Daniel Danner, and Silke Martin. 2016. "The association between personality and cognitive ability: Going beyond simple effects." Journal of Research in Personality 62:39-44. 
Reuben, Ernesto, Paola Sapienza, and Luigi Zingales. 2015. "Taste for competition and the gender gap among young business professionals." Working paper .

Reuben, Ernesto, Matthew Wiswall, and Basit Zafar. 2017. "Preferences and Biases in Educational Choices and Labor Market Expectations: Shrinking the Black Box of Gender." Economic Journal 127 (604):2153-2186.

Rosenberg, Morris. 1965. Society and the adolescent self-image. Princeton, NJ: Princeton University Press.

Ryckman, Richard M, Max Hammer, Linda M Kaczor, and Joel A Gold. 1990. "Construction of a hypercompetitive attitude scale." Journal of Personality Assessment 55 (3-4):630-639.

Samek, Anya. 2019. "Gender differences in job entry decisions: A university-wide field experiment." Management Science 65 (7):3272-3281.

Schmitt, David P, Anu Realo, Martin Voracek, and Jüri Allik. 2008. "Why can't a man be more like a woman? Sex differences in Big Five personality traits across 55 cultures." Journal of Personality and Social Psychology 94 (1):168.

Shurchkov, Olga and Catherine C Eckel. 2018. "Gender Differences in Behavioral Traits and Labor Market Outcomes." In The Oxford Handbook of Women and the Economy. Oxford University Press.

Smither, Robert D and John M Houston. 1992. "The nature of competitiveness: The development and validation of the competitiveness index." Educational and Psychological Measurement $52(2): 407-418$.

Urbig, Diemo, Werner Bönte, Vivien D Procher, and Sandro Lombardo. 2019. "Entrepreneurs embrace competition: evidence from a lab-in-the-field study." Small Business Economics :1-22.

van Veldhuizen, Roel. 2017. "Gender Differences in Tournament Choices: Risk Preferences, Overconfidence or Competitiveness?" Working paper .

Zhang, Y. Jane. 2012. "Can experimental economics explain competitive behavior outside the lab?" Working paper. 


\section{Appendix A: Additional graphs and tables}

Figure A1: Predictive power of individual traits compared: effect of moving from bottom 30 percent to top 30 percent not conditioning on other traits

Effect on gross monthly income (cond. on education)
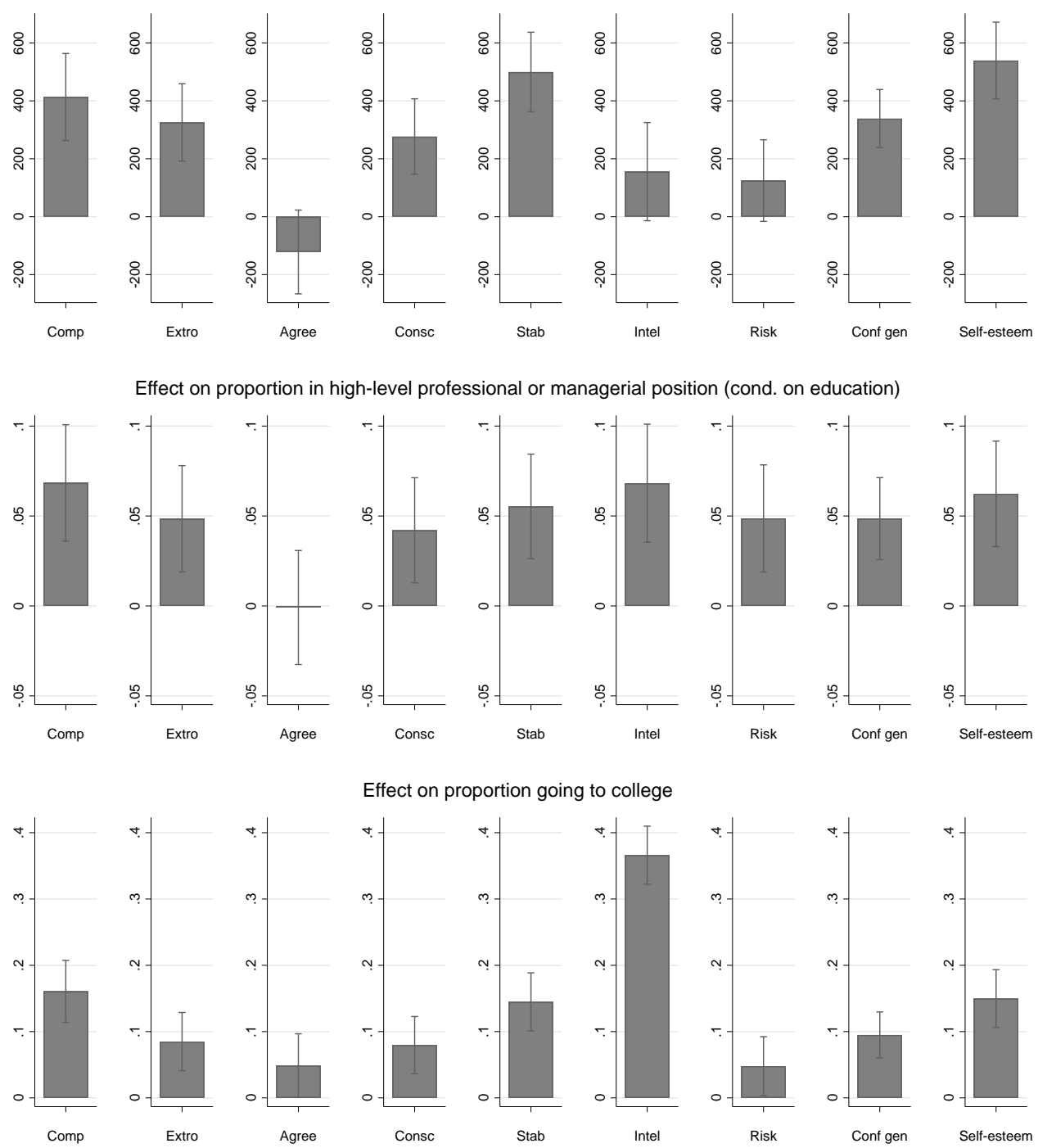

Effect on proportion going to college
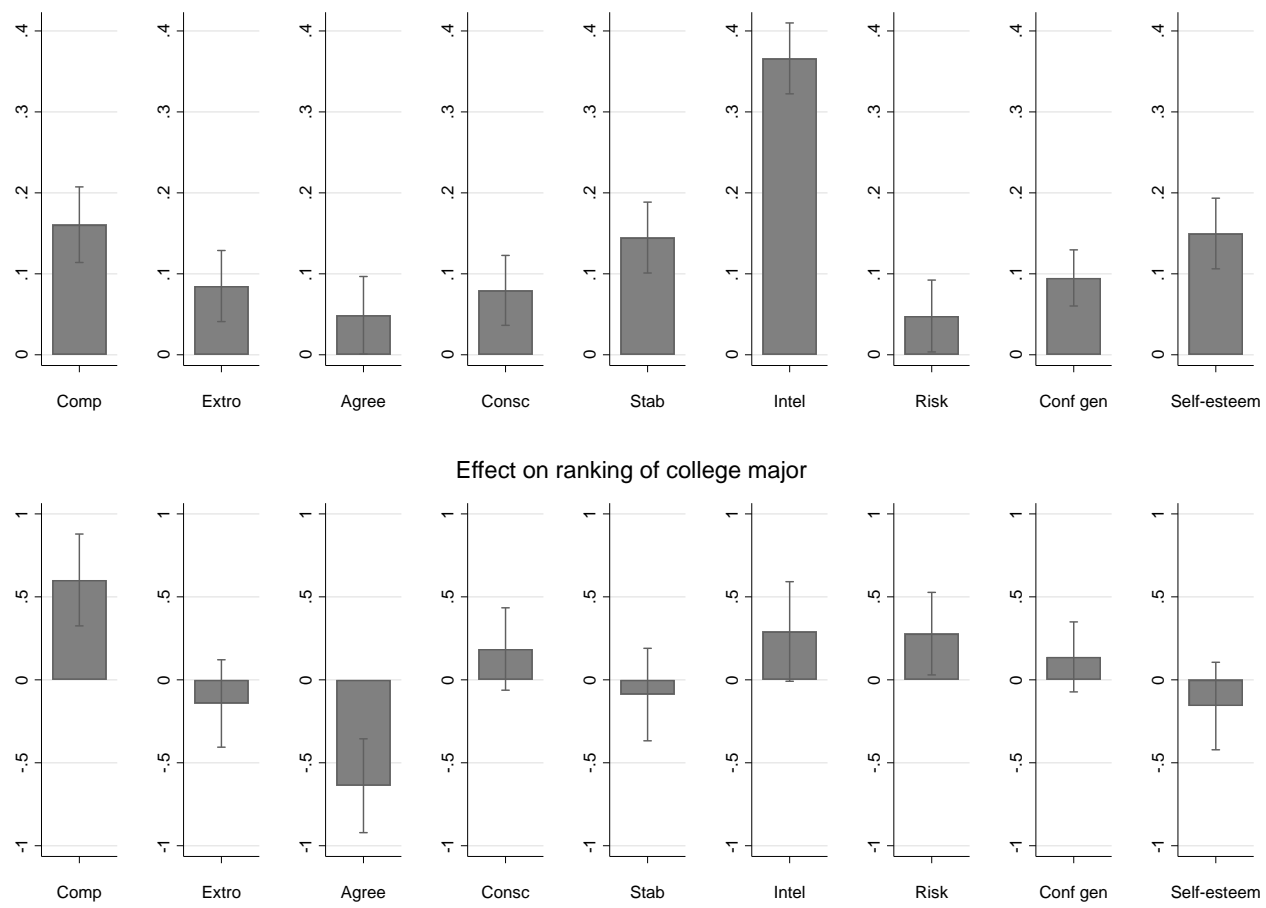

Effect on ranking of college major
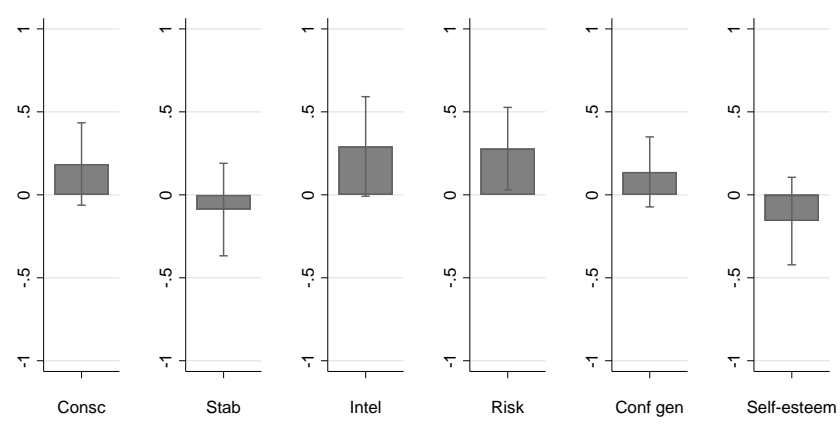

Note: Each figure shows the coefficient from a separate OLS regression of a dummy indicating that a respondent is in the top 30\% (vs bottom 30\%) on a given trait on an outcome variable. Each coefficient is from a separate regression controlling for gender, age, education level (in the case of the first two graphs). The sample in each regression consists of respondents aged between 25 and 65 who are either in the bottom or top 30 percent on the given trait. Error bars represent 95-percent confidence intervals. 
Figure A2: Predictive power of individual traits compared (whole sample): effect on R-squared not controlling for other traits
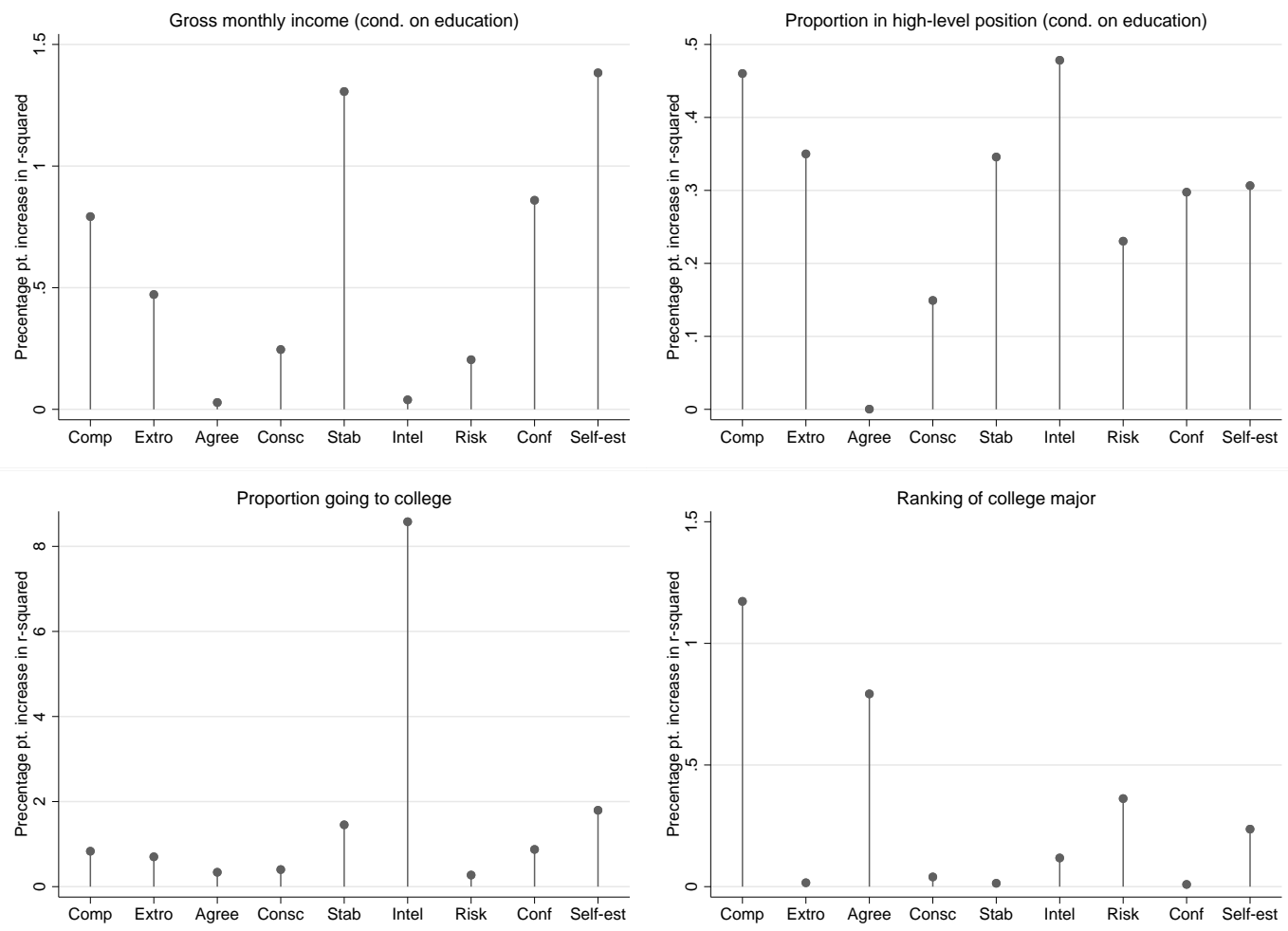

Note: the figures show the percentage point increase in R-squared in OLS regressions of a given trait variable on an outcome variable. Each effect is from a separate regression controlling for gender, age and (in the case of the first two graphs) education level. The sample consists of respondents aged between 25 and 65 .

Figure A3: Gender differences in individual traits
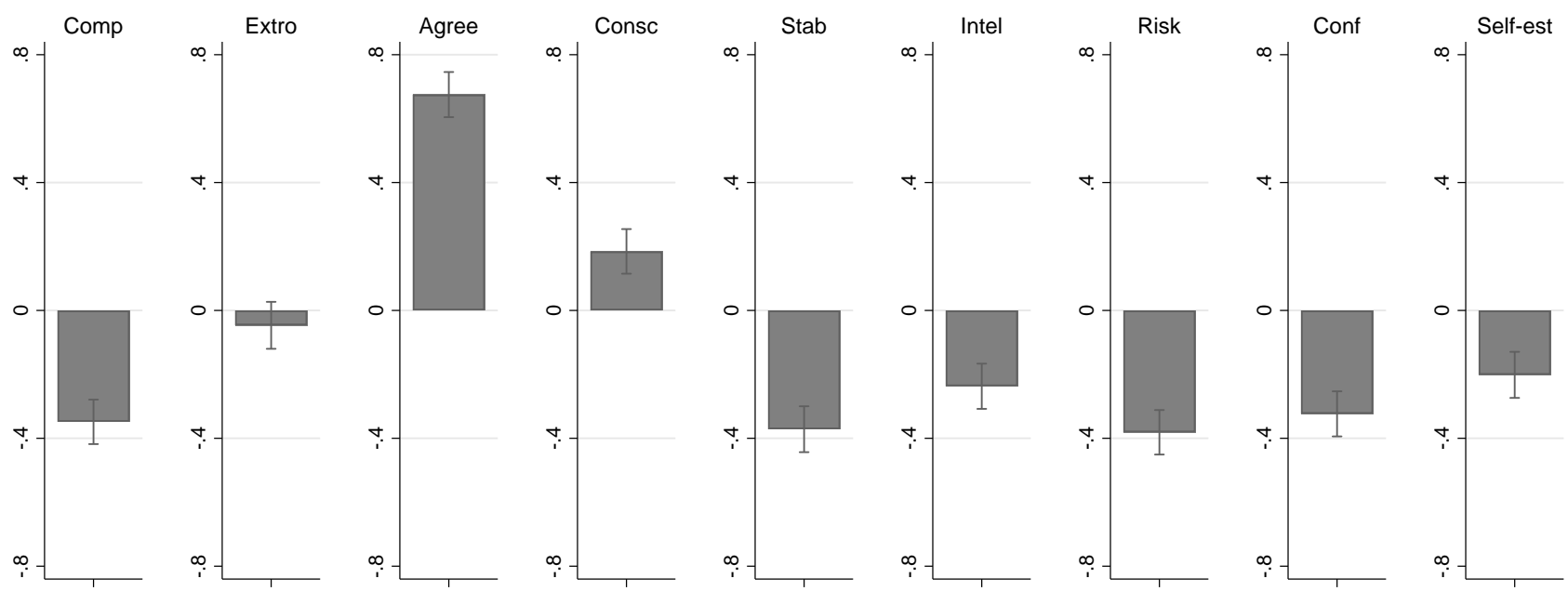

Note: Figures shows the difference between women and men in each trait measure. The trait measures have been standardized to have mean zero and standard deviation one. Error bars represent 95-percent confidence intervals. 
Table A1: Correlation matrices for individual traits

Experimental sample:

\begin{tabular}{|c|c|c|c|c|c|c|c|c|c|c|}
\hline & $\begin{array}{c}\text { Compete } \\
(\exp )\end{array}$ & $\begin{array}{l}\text { Conf. } \\
(\exp )\end{array}$ & $\begin{array}{l}\text { Competi- } \\
\text { tiveness }\end{array}$ & $\begin{array}{c}\text { Risk } \\
\text { seeking }\end{array}$ & $\begin{array}{l}\text { Conf. } \\
\text { (hyp) }\end{array}$ & $\begin{array}{l}\text { Conf. } \\
\text { (gen) }\end{array}$ & $\begin{array}{l}\text { Extro- } \\
\text { version }\end{array}$ & $\begin{array}{l}\text { Agreea- } \\
\text { bleness }\end{array}$ & $\begin{array}{l}\text { Conscien- } \\
\text { tiousness }\end{array}$ & $\begin{array}{c}\text { - Stabi- Intel. Self- } \\
\text { lity open. esteem }\end{array}$ \\
\hline Compete $(\exp )$ & 1.0000 & & & & & & & & & \\
\hline Confidence (exp) & 0.3076 & 1.0000 & & & & & & & & \\
\hline Competitiveness & 0.1543 & 0.1779 & 1.0000 & & & & & & & \\
\hline Risk seeking & 0.1178 & 0.1733 & 0.3980 & 1.0000 & & & & & & \\
\hline Confidence (hyp) & 0.0588 & 0.0986 & 0.0337 & -0.0154 & 1.0000 & & & & & \\
\hline Confidence (gen) & 0.0583 & 0.0922 & 0.1451 & 0.1865 & 0.0526 & 1.0000 & & & & \\
\hline Extroversion & 0.0403 & 0.1388 & 0.2732 & 0.3070 & -0.0058 & 0.2919 & 1.0000 & & & \\
\hline Agreeableness & -0.0620 & -0.0495 & -0.0200 & -0.0008 & -0.0441 & 0.0925 & 0.3085 & 1.0000 & & \\
\hline Conscientiousness & -0.0166 & -0.0143 & 0.0946 & -0.0402 & 0.0481 & 0.2604 & 0.1105 & 0.2626 & 1.0000 & \\
\hline Stability & 0.1001 & 0.1625 & 0.1211 & 0.1666 & 0.0571 & 0.5145 & 0.2203 & 0.0324 & 0.2735 & 1.0000 \\
\hline Intellectual open. & 0.1377 & 0.1810 & 0.1739 & 0.1744 & 0.0619 & 0.3136 & 0.3362 & 0.2331 & 0.2164 & 0.20021 .0000 \\
\hline Self-esteem & 0.0533 & 0.1161 & 0.1648 & 0.1416 & 0.0460 & 0.7148 & 0.3284 & 0.1295 & 0.3451 & 0.64880 .28881 .0000 \\
\hline
\end{tabular}

\section{Whole sample:}

\begin{tabular}{r|cccccccccc} 
& $\begin{array}{c}\text { Competi- } \\
\text { tiveness }\end{array}$ & $\begin{array}{c}\text { Risk } \\
\text { seeking }\end{array}$ & $\begin{array}{c}\text { Conf. } \\
\text { (hyp) }\end{array}$ & $\begin{array}{c}\text { Conf. } \\
\text { (gen) }\end{array}$ & $\begin{array}{c}\text { Extro- } \\
\text { version }\end{array}$ & $\begin{array}{c}\text { Agreea- } \\
\text { bleness }\end{array}$ & $\begin{array}{c}\text { Conscien- } \\
\text { tiousness }\end{array}$ & Stability & $\begin{array}{c}\text { Intel. } \\
\text { open. }\end{array}$ & $\begin{array}{c}\text { Self- } \\
\text { esteem }\end{array}$ \\
\hline Competitiveness & 1.0000 & & & & & & & & & \\
Risk seeking & 0.3815 & 1.0000 & & & & & & & & \\
Confidence (hyp) & 0.0071 & -0.0259 & 1.0000 & & & & & & & \\
Confidence (gen) & 0.1608 & 0.1786 & 0.0287 & 1.0000 & & & & & & \\
Extroversion & 0.2668 & 0.2931 & 0.0010 & 0.3076 & 1.0000 & & & & \\
Agreeableness & -0.0199 & -0.0240 & -0.0213 & 0.1145 & 0.3046 & 1.0000 & & & \\
Conscientiousness & 0.1082 & -0.0559 & -0.0014 & 0.2911 & 0.1306 & 0.2826 & 1.0000 & & \\
Stability & 0.1123 & 0.1606 & 0.0588 & 0.4813 & 0.2591 & 0.0523 & 0.2600 & 1.0000 & \\
Intellectual open. & 0.1638 & 0.1728 & 0.0471 & 0.3440 & 0.3323 & 0.2145 & 0.2286 & 0.1954 & 1.0000 \\
Self-esteem & 0.1426 & 0.1258 & 0.0320 & 0.7163 & 0.3691 & 0.1724 & 0.3584 & 0.6268 & 0.3084 & 1.0000
\end{tabular}


Appendix B: Results for hypothetical Niederle-Vesterlund tournament entry decision 
Table B1: Career outcomes and hypothetical NV decision

\begin{tabular}{|c|c|c|c|c|c|c|c|}
\hline & (1) & $(2)$ & (3) & (4) & (5) & (6) & $(7)$ \\
\hline \multicolumn{8}{|c|}{ A. Monthly gross income (OLS) } \\
\hline Compete & $\begin{array}{c}484.3^{* * *} \\
(63.9)\end{array}$ & $\begin{array}{c}264.6^{* * *} \\
(58.0)\end{array}$ & $\begin{array}{c}186.3^{* * *} \\
(56.7)\end{array}$ & $\begin{array}{c}187.0^{* * * *} \\
(57.1)\end{array}$ & $\begin{array}{c}147.0^{* * *} \\
(51.9)\end{array}$ & $\begin{array}{c}102.3^{* *} \\
(51.5)\end{array}$ & $\begin{array}{l}91.7^{*} \\
(51.6)\end{array}$ \\
\hline $\mathrm{N}$ & 2886 & 2886 & 2886 & 2886 & 2883 & 2883 & 2883 \\
\hline adj. R-sq & 0.021 & 0.207 & 0.248 & 0.253 & 0.366 & 0.382 & 0.385 \\
\hline \multicolumn{8}{|c|}{ B. Monthly gross income (quantile regression: 20th decile) } \\
\hline Compete & $\begin{array}{c}311.7^{* * *} \\
(73.4)\end{array}$ & $\begin{array}{c}70.0 \\
(84.8)\end{array}$ & $\begin{array}{c}16.4 \\
(78.0)\end{array}$ & $\begin{array}{c}24.5 \\
(77.0)\end{array}$ & $\begin{array}{c}54.5 \\
(84.9)\end{array}$ & $\begin{array}{c}0.2 \\
(76.8)\end{array}$ & $\begin{array}{c}34.4 \\
(79.3)\end{array}$ \\
\hline & 2886 & 2886 & 2886 & 2886 & 2883 & 2883 & 2883 \\
\hline \multicolumn{8}{|c|}{ C. Monthly gross income (quantile regression: median) } \\
\hline Compete & $\begin{array}{c}440.0^{* * *} \\
(75.9)\end{array}$ & $\begin{array}{c}311.8^{* * *} \\
(75.2)\end{array}$ & $\begin{array}{c}196.6^{* * *} \\
(69.4)\end{array}$ & $\begin{array}{c}201.2^{* * *} \\
(70.8)\end{array}$ & $\begin{array}{c}125.6^{* *} \\
(54.9)\end{array}$ & $\begin{array}{c}63.9 \\
(58.0)\end{array}$ & $\begin{array}{c}36.3 \\
(60.1)\end{array}$ \\
\hline & 2886 & 2886 & 2886 & 2886 & 2883 & 2883 & 2883 \\
\hline \multicolumn{8}{|c|}{ D. Monthly gross income (quantile regression: 80th decile) } \\
\hline Compete & $\begin{array}{c}700.0^{* * *} \\
(97.9)\end{array}$ & $\begin{array}{c}422.1^{* * * *} \\
(99.2)\end{array}$ & $\begin{array}{c}318.0^{* * *} \\
(88.0)\end{array}$ & $\begin{array}{c}249.2^{* * *} \\
(91.5)\end{array}$ & $\begin{array}{c}153.0^{* *} \\
(74.4)\end{array}$ & $\begin{array}{c}157.8^{* *} \\
(80.2)\end{array}$ & $\begin{array}{c}86.2 \\
(80.0)\end{array}$ \\
\hline & 2886 & 2886 & 2886 & 2886 & 2883 & 2883 & 2883 \\
\hline \multicolumn{8}{|c|}{ E. High-level professional or managerial position (OLS) } \\
\hline Compete & $\begin{array}{c}0.106^{* * *} \\
(0.016)\end{array}$ & $\begin{array}{c}0.083^{* * *} \\
(0.016)\end{array}$ & $\begin{array}{c}0.063^{* * *} \\
(0.015)\end{array}$ & $\begin{array}{c}0.064^{* * *} \\
(0.016)\end{array}$ & $\begin{array}{c}0.045^{* * *} \\
(0.014)\end{array}$ & $\begin{array}{c}0.038^{* * *} \\
(0.014)\end{array}$ & $\begin{array}{c}0.035^{* *} \\
(0.014)\end{array}$ \\
\hline$\overline{\mathrm{N}}$ & 2972 & 2972 & 2972 & 2972 & 2970 & 2970 & 2970 \\
\hline adj. R-sq & 0.017 & 0.043 & 0.099 & 0.099 & 0.285 & 0.292 & 0.291 \\
\hline \multicolumn{8}{|c|}{ F. Occupation (ordered probit) } \\
\hline Compete & $\begin{array}{c}0.215^{* * *} \\
(0.042)\end{array}$ & $\begin{array}{c}0.177^{* * *} \\
(0.043)\end{array}$ & $\begin{array}{c}0.113^{* * *} \\
(0.043)\end{array}$ & $\begin{array}{c}0.103^{* *} \\
(0.044)\end{array}$ & $\begin{array}{c}0.085^{* *} \\
(0.043)\end{array}$ & $\begin{array}{c}0.047 \\
(0.044)\end{array}$ & $\begin{array}{c}0.023 \\
(0.045)\end{array}$ \\
\hline $\mathrm{N}$ & 2972 & 2972 & 2972 & 2972 & 2970 & 2970 & 2970 \\
\hline \multicolumn{8}{|l|}{ E. College (OLS) } \\
\hline Compete & $\begin{array}{c}0.097^{* * *} \\
(0.019)\end{array}$ & $\begin{array}{c}0.081^{* * *} \\
(0.019)\end{array}$ & $\begin{array}{c}0.059^{* * *} \\
(0.019)\end{array}$ & $\begin{array}{c}0.063^{* * *} \\
(0.019)\end{array}$ & & & \\
\hline $\mathrm{N}$ & 3079 & 3079 & 3079 & 3079 & & & \\
\hline adj. R-sq & 0.008 & 0.039 & 0.127 & 0.129 & & & \\
\hline \multicolumn{8}{|c|}{ F. Education level (ordered probit) } \\
\hline Compete & $\begin{array}{c}0.250^{* * *} \\
(0.041)\end{array}$ & $\begin{array}{c}0.206^{* * *} \\
(0.042)\end{array}$ & $\begin{array}{c}0.165^{* * *} \\
(0.042)\end{array}$ & $\begin{array}{c}0.189^{* * *} \\
(0.044)\end{array}$ & & & \\
\hline$\overline{\mathrm{N}}$ & 3079 & 3079 & 3079 & 3079 & & & \\
\hline \multicolumn{8}{|c|}{ H. College major (ordered probit) } \\
\hline Compete & $\begin{array}{c}0.347^{* * *} \\
(0.067)\end{array}$ & $\begin{array}{c}0.208^{* * *} \\
(0.069)\end{array}$ & $\begin{array}{c}0.202^{* * *} \\
(0.071)\end{array}$ & $\begin{array}{c}0.188^{* * *} \\
(0.072)\end{array}$ & & & \\
\hline $\mathrm{N}$ & 1002 & 1002 & 1002 & 1002 & & & \\
\hline Gender, age & & $\sqrt{ }$ & $\sqrt{ }$ & $\sqrt{ }$ & $\sqrt{ }$ & $\sqrt{ }$ & $\sqrt{ }$ \\
\hline Education level & & & & & $\sqrt{ }$ & $\sqrt{ }$ & $\sqrt{ }$ \\
\hline Big 5 & & & $\sqrt{ }$ & $\sqrt{ }$ & & $\sqrt{ }$ & $\sqrt{ }$ \\
\hline Confidence and risk & 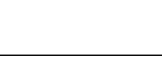 & & . & $\sqrt{ }$ & & & $\sqrt{ }$ \\
\hline
\end{tabular}


Figure B1: Hypothetical competition choice and career outcomes
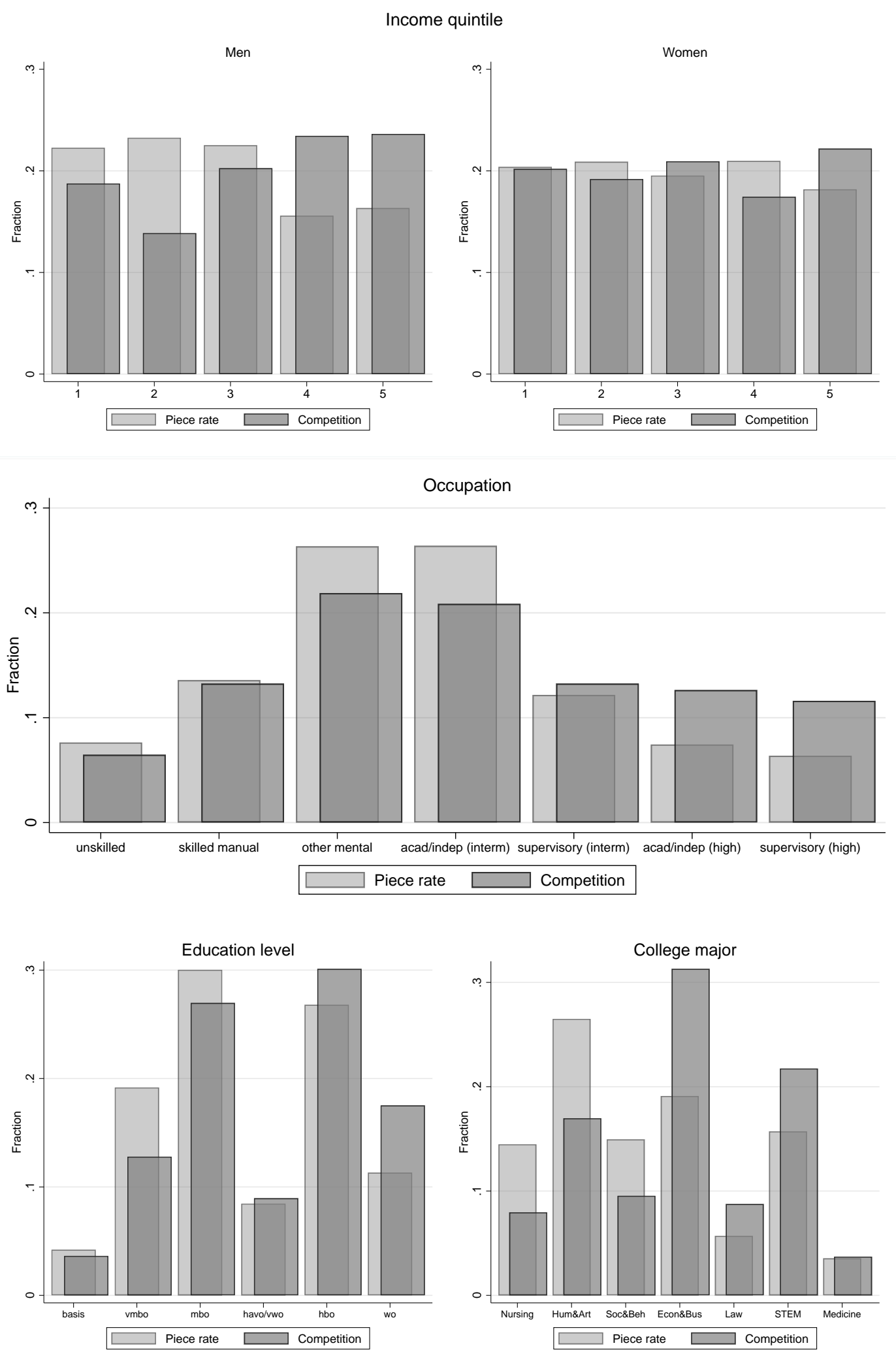

Note: The figures show the distribution of participants across different values of our outcome variables separately for survey respondents who chose to compete/not to compete on the hypothetical Niederle-Vesterlund question. The classifications of occupational levels, education levels and college majors are explained in Section 2.3. 
Figure B2: Predictive power of individual traits compared using both competitiveness measures: effect on R-squared conditional on all other traits
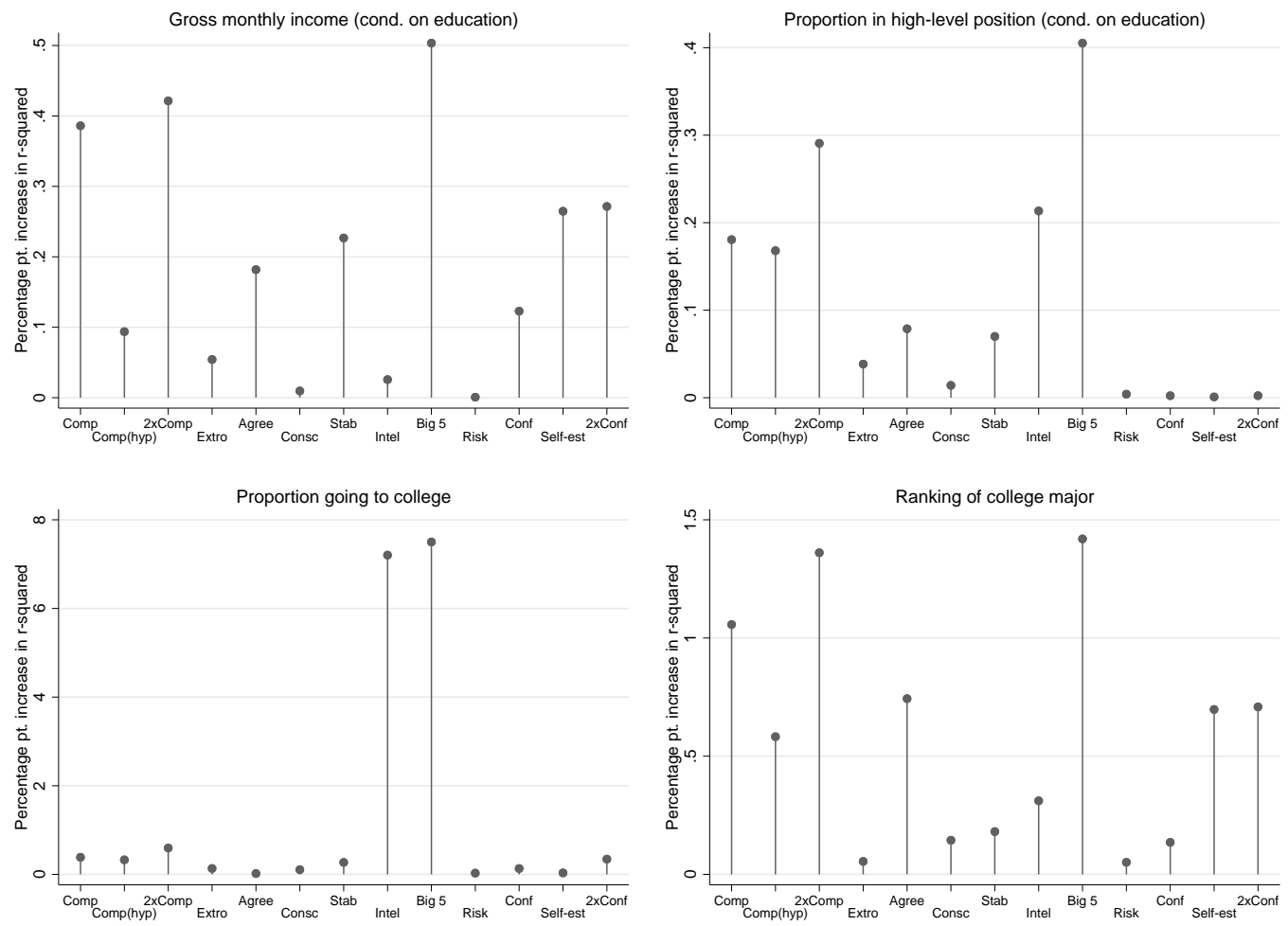

Note: The figures show the percentage point increase in R-squared in OLS regressions of a given trait variable on an outcome variable. Each effect is from a separate regression controlling for gender, age, education level (in the case of the first two graphs), and all other traits (with the exception of confidence and self-esteem where we control for all other traits except the other confidence measure). The sample consists of respondents aged between 25 and 65 . 
Figure B3: Percentage reduction in gender differences when adding each individual trait separately and jointly (using both questionnaire measures of competitiveness)
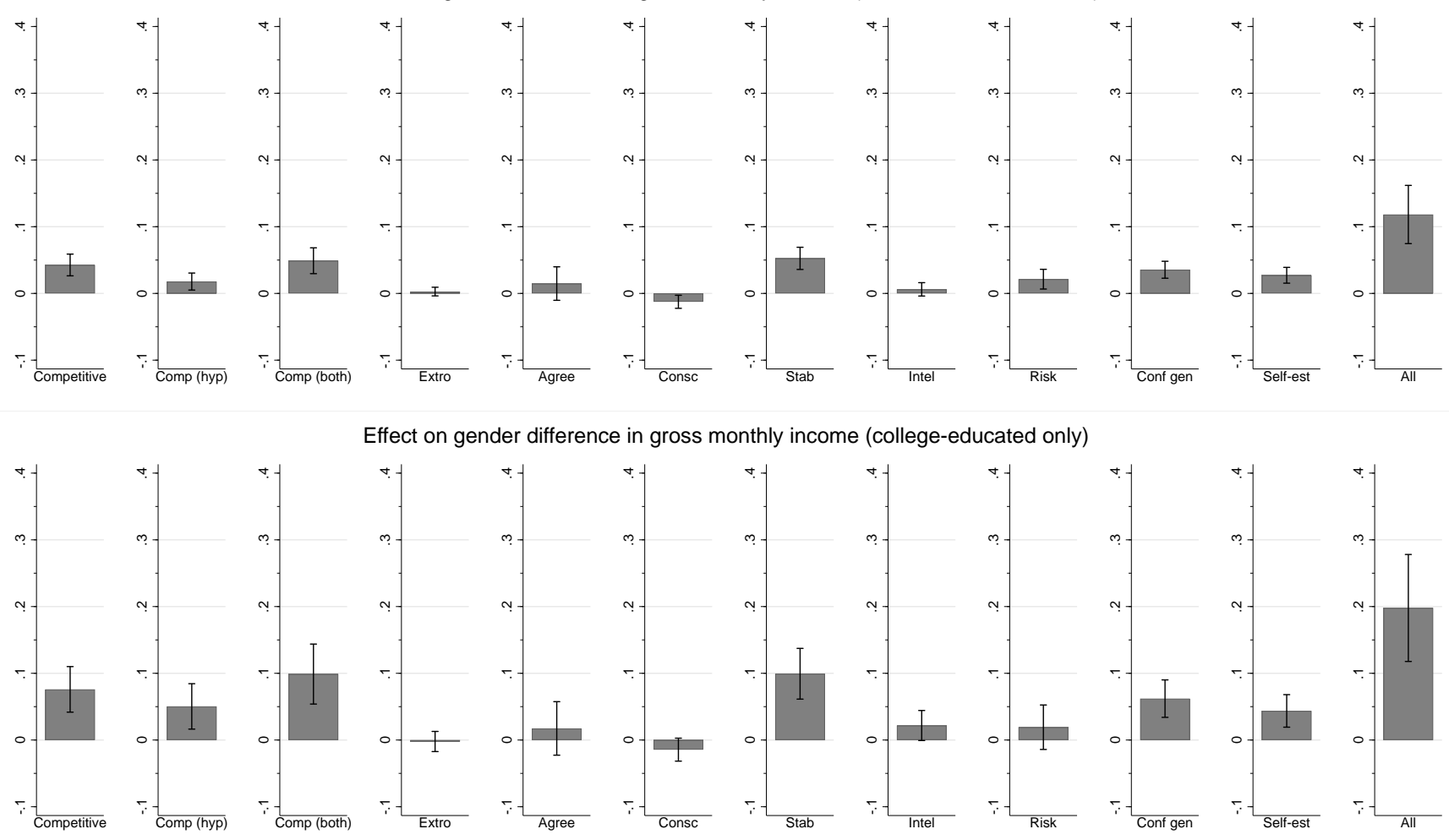

Effect on gender difference in gross monthly income (college-educated only)
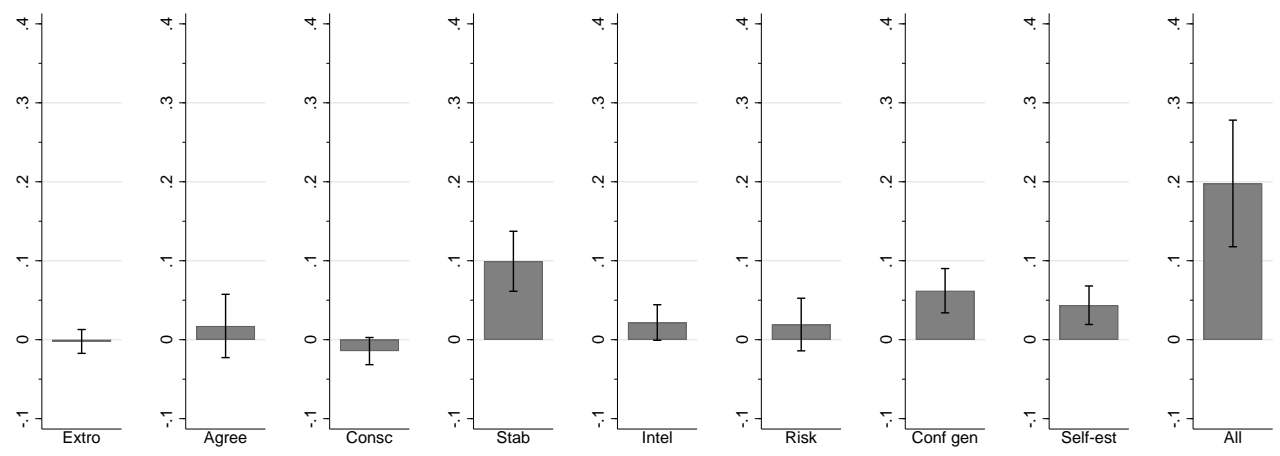

Effect on gender difference in proportion in high-level professional or managerial position (cond. on education level)
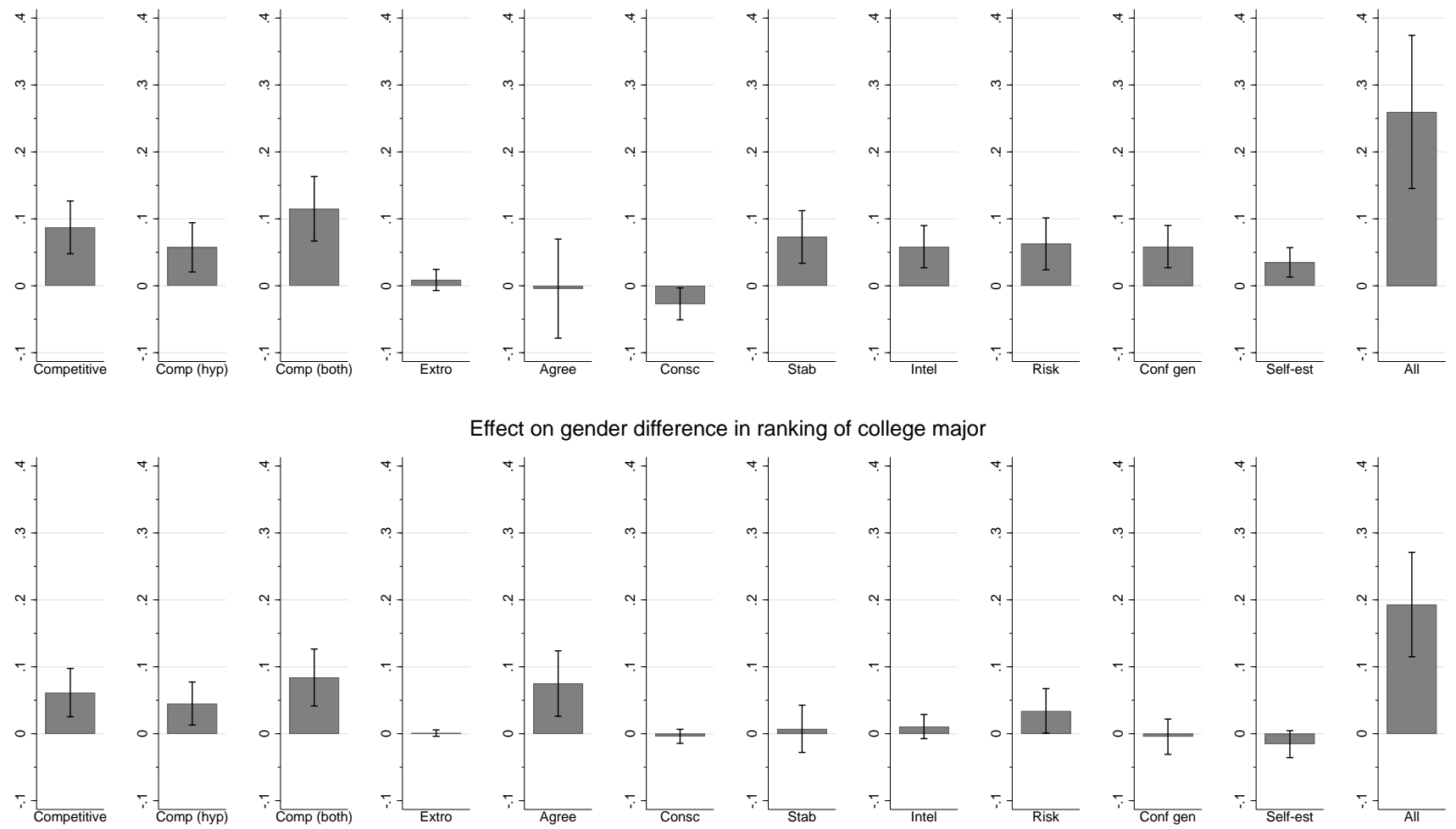

Effect on gender difference in ranking of college major
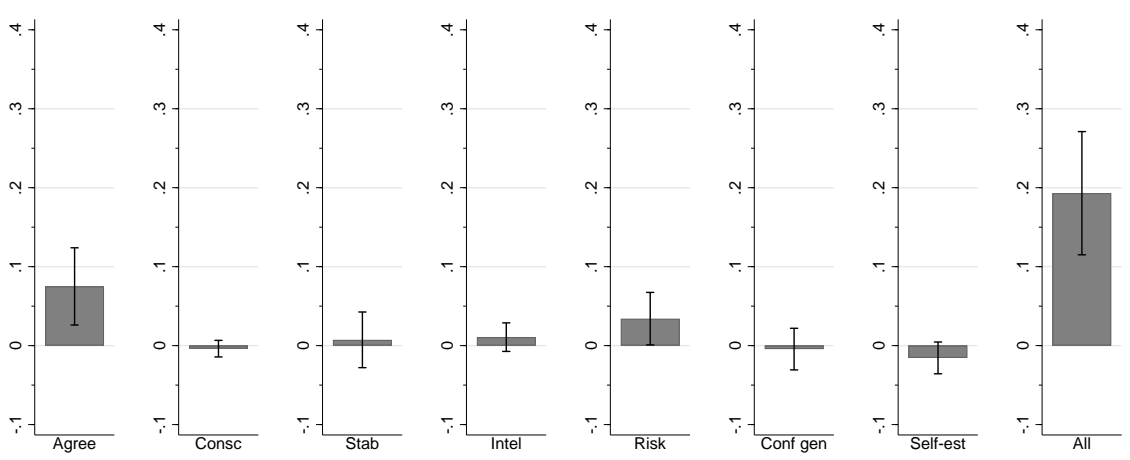

Note: The figures show the part (in percent) of the gender gap in an outcome variable that can be explained by each trait separately and jointly. The estimates are from separate OLS regressions of gender, age, and age squared on an outcome variable with and without a trait variable added to the regression. The sample consists of respondents aged between 25 and 65 . Error bars represent 95-percent confidence intervals. 